\title{
Analyzing Vibration Mechanism of Angular Contact Ball Bearing with Compound Faults on Inner and Outer Rings
}

\author{
Lihai Chen $\mathbb{D}^{1,}{ }^{1,2,3}$ Ma Fang $\mathbb{D}^{2},{ }^{2}$ Ming Qiu $\mathbb{D}^{1,3}$ Yanfang Dong $\mathbb{D}^{1,3}$ Xiaoxu Pang $\mathbb{D}^{1,3}$ \\ Junxing $L i\left(\mathbb{C},{ }^{1,3}\right.$ and Chuanmeng Yang $\mathbb{C}^{1,3}$ \\ ${ }^{1}$ School of Mechatronics Engineering, Henan University of Science and Technology, Luoyang 471003, China \\ ${ }^{2}$ AECC Harbin Bearing Co.,Ltd., Harbin 150000, China \\ ${ }^{3}$ Collaborative Innovation Center of Machinery Equipment Advanced Manufacturing of Henan Province, \\ Henan University of Science and Technology, Luoyang 471003, China
}

Correspondence should be addressed to Yanfang Dong; xiaoqidong104@163.com

Received 1 April 2021; Revised 30 October 2021; Accepted 10 November 2021; Published 2 December 2021

Academic Editor: Antonio Batista

Copyright (c) 2021 Lihai Chen et al. This is an open access article distributed under the Creative Commons Attribution License, which permits unrestricted use, distribution, and reproduction in any medium, provided the original work is properly cited.

\begin{abstract}
This paper investigates a method to dynamically model compound faults on the inner and outer rings of an angular contact ball bearing as well as their effects on its dynamic behavior. Gupta's dynamic modeling method is used to consider changes in the deformation and direction of the contact load when the ball passes through the damaged area and to develop a dynamic model of compound faults in the angular contact ball bearing. The step-changing fourth-order Runge-Kutta method is used to solve the dynamic compound fault model. The time-domain signal of vibration responses in the case of a single fault in the inner and outer rings exhibited a certain periodicity, and the frequency of faults in the envelope spectrum was clear. By comparison, the periodicity of compound faults was not clear. The signals of compound faults were decomposed by the dual-tree complex wavelet transform to identify their characteristic frequency. Errors occurred between the characteristic frequency of the theoretical fault and its simulated value. They increased with the rotational speed and decreased with an increase in axial load, whereas the influence of radial load on them was minor. For compound faults on the inner and outer rings of an angular contact ball bearing, this study provides a modeling method that can describe changes in the deformation and direction of the contact load when the ball passes through the damaged area of the inner and outer rings. The work here can provide an important foundation for fault identification in angular contact ball bearings.
\end{abstract}

\section{Introduction}

Angular contact ball bearings (ACBBs) play an important role in the safety and reliability of mechanical systems. However, localized defects due to fatigue, abrasion, and skidding scratches easily occur on raceways and can significantly affect the performance of such systems. To reduce the possibility of damage to the system owing to localized defects in the bearings, their precise and early recognition is important. Many signal processing techniques have been used to identify the characteristic frequency of the localized defects based on the impulse characteristics of the vibration signals of defective bearings [1], including wavelet and correlation filtering
$[2,3]$, time-frequency ridge enhancement [4], intrinsic time-scale decomposition [5], integrated spectral coherence [6], spectral kurtosis [7], and the sparsity-based algorithm [8].

A dynamic model of ACBBs with localized defects can be used to investigate and predict their vibrational characteristics. According to whether the rotational characteristics of the bearing elements are considered, such dynamic models can be divided into two types: the simplified spring-mass model and the complete dynamics model. The simplified spring-mass model uses a nonlinear spring and damping to handle the contact characteristics between the balls and the raceways. The dynamic model has been proposed to investigate the effects of multipoint faults in the races on 
vibrations in deep groove ball bearings [9]. A dynamic model has been proposed for a ball bearing with combined defects, including surface waviness and localized defects $[10,11]$. The statistical features of ball bearings based on a simplified spring-mass model have been examined to assess spalling propagation [12]. A complete dynamic model was first presented by Gupta [13], in which the motions of each element were described by differential equations. Many dynamic fault models have been built based on Gupta's model. To investigate the dynamics and vibrational responses of ACBBs with ball defects, a dynamic model with five degrees of freedom was proposed [14]. An improved time-dependent displacement excitation model was established to consider coupling errors, including roundness and waviness in the inner and outer races of an ACBB [15]. A high-speed fault dynamic model of ACBBs with defects in the races was built by using a $\mathrm{B}$-spline fitting displacement excitation method to represent fault excitation [16]. The effects of cage pocket wear on the dynamic characteristics of ball bearings have been investigated by using a complete dynamics model $[17,18]$.

Some limitations persist in the literature: (1) Simplified models cannot describe complex dynamic behavior and usually focus on the characteristics of planar motion. They are thus not suitable to deal with ACBBs. (2) In the processing for complete dynamic modeling, the fault excitation is characterized by some impulse function that cannot describe changes in the deformation and direction of the contact load when the ball passes through the damaged area. (3) Methods to analyze the vibration mechanism of ACBBs with compound faults on inner and outer rings have rarely been studied.

In this paper, a dynamic model of compound faults in ball bearings based on Gupta's model is established by considering changes in the deformation and direction of the contact load when the ball passes through the damaged area. Simulations are conducted to analyze the mechanism of vibration of ACBBs with compound faults on the inner and outer rings. The correctness of the proposed model was verified through experiments, and errors between the theoretical and the simulated characteristic fault frequencies are explained. This can provide an important foundation for fault diagnosis in ball bearings.

\section{Dynamic Model of Ball Bearing}

We used Gupta's method [13] to formulate a dynamic model of angular contact ball bearings with compound faults on the inner and outer rings. We assumed that the centers of mass of elements of the bearing coincide with their geometric centers and that the cage pocket is cylindrical. Hertz contact theory and Coulomb's friction law are used to calculate the normal and tangential forces of all elements.

2.1. Coordinate Systems. Some coordinate systems are defined to describe the relative position and motion of elements of the bearing, as shown in Figure 1, as follows:

(1) $O-X-Y-Z$ is the inertial coordinate system.

(2) $o_{b}-x_{b}-y_{b}-z_{b}$ is the body-fixed coordinate system of the ball.

(3) $o_{r}-x_{r}-y_{r}-z_{r}$ is the body-fixed coordinate system of the ring.

(4) $o_{c}-x_{c}-y_{c}-z_{c}$ is the body-fixed coordinate system of the cage.

(5) $o_{p}-x_{p}-y_{p}-z_{p}$ is the coordinate system of the cage pockets.

Other local coordinate systems are constructed as needed.

The transformation matrix $\mathrm{A}$ is obtained by using the Cardin angles[13] as follows:

$$
A(\eta, \xi, \lambda)=\left[\begin{array}{ccc}
\cos \xi \cos \lambda & \cos \eta \sin \lambda+\sin \eta \sin \xi \cos \lambda & \sin \eta \cos \lambda-\cos \eta \sin \xi \cos \lambda \\
-\cos \xi \sin \lambda & \cos \eta \cos \lambda-\sin \eta \sin \xi \sin \lambda & \sin \eta \cos \lambda+\cos \eta \sin \xi \sin \lambda \\
\sin \xi & -\sin \eta \cos \xi & \cos \eta \cos \xi
\end{array}\right] .
$$

2.2. Interactions between Ball and Rings. According to the geometric relationship shown in Figure 2, the position vector from the ball to the inner ring in the body-fixed coordinate system of the ring can be expressed as follows:

$$
\begin{aligned}
& \mathbf{r}_{\mathrm{br}}^{r}=\mathbf{A}_{\mathrm{ir}}\left(\mathbf{r}_{b}^{i}-\mathbf{r}_{r}^{i}\right), \\
& \mathbf{A}_{\mathrm{ir}}=\mathbf{A}\left(\varphi_{r 1}, \varphi_{r 2}, \varphi_{r 3}\right),
\end{aligned}
$$

where $\mathbf{A}_{i r}$ is the transformation matrix from the O-X-Y-Z coordinate system to the $o_{r}-x_{r}-y_{r}-z_{r}$ coordinate system, and $\varphi_{r 1}, \varphi_{r 1}$, and $\varphi_{r 3}$ are the attitude angles of the inner ring.

Then, the angular position $\theta_{b r}$ of the ball in the inner race coordinate system is obtained as follows:

$$
\theta_{\mathrm{br}}=\arctan \left(\frac{-\mathbf{r}_{\mathrm{br}(2)}^{r}}{\mathbf{r}_{\mathrm{br}(3)}^{r}}\right) .
$$

The vector from the center of curvature of the inner race to the center of the ball in the azimuth coordinate system is

$$
\begin{aligned}
\mathbf{r}_{\mathrm{bc}}^{a} & =\mathbf{A}_{\mathrm{ia}} \mathbf{A}_{\mathrm{ri}}\left(\mathbf{r}_{\mathrm{br}}^{r}-\mathbf{r}_{\mathrm{cr}}^{r}\right), \\
\mathbf{A}_{\mathrm{ia}} & =\mathbf{A}\left(\theta_{\mathrm{br}}, 0,0\right), \\
\mathbf{r}_{\mathrm{cr}}^{r} & =\left[0,-r_{f} \sin \theta_{\mathrm{br}}, r_{f} \cos \theta_{\mathrm{br}}\right], \\
r_{f} & =0.5 d_{r}+\mathrm{fD},
\end{aligned}
$$




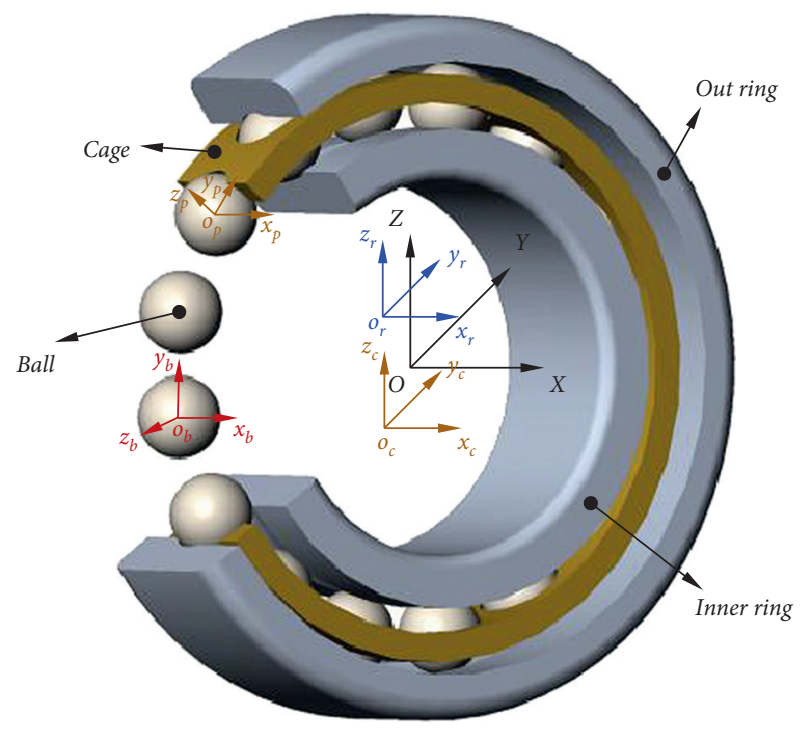

Figure 1: Coordinate systems.

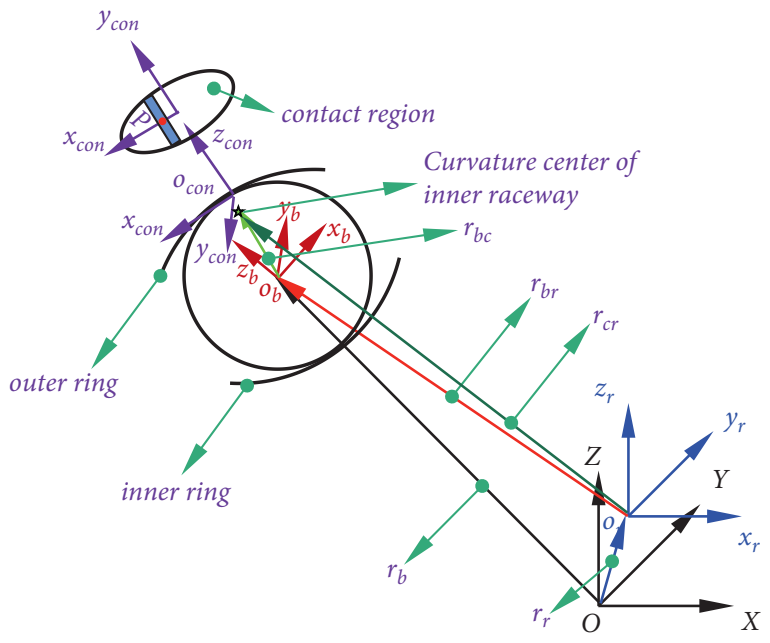

Figure 2: Positional relationships of the ball and rings.

where $d_{r}$ is the diameter of the bottom of the groove of the raceway, $f$ is the curvature factor of the bottom of the groove of the inner raceway, and $D$ is the diameter of the ball.

The contact angle between the inner race and the ball can be calculated as follows:

$$
\alpha=\arctan \left(\frac{\mathbf{r}_{\mathrm{bc}(1)}^{a}}{\mathbf{r}_{\mathrm{bc}(3)}^{a}}\right) .
$$

The vector from the center of curvature of the inner race to the center of the ball in the contact coordinate system is

$$
\begin{aligned}
\mathbf{r}_{\mathrm{bc}}^{\mathrm{con}} & =\mathbf{A}_{\mathrm{acon}} \mathbf{r}_{\mathrm{bc}}^{a}, \\
\mathbf{A}_{\mathrm{acon}} & =\mathbf{A}(0, \alpha, 0) .
\end{aligned}
$$

Contact deformation between the inner ring and the ball can be given as follows:

$$
\delta=\mathbf{r}_{\mathrm{bc}(3)}^{\mathrm{con}}-(f-0.5) D .
$$

Although there is a film of oil between the ball and the raceway, it does not affect the distribution of the contact load. The contact force can thus be obtained according to Hertz's theory as follows:

$$
\begin{aligned}
& F_{n}=\left\{\begin{array}{ll}
0 & \delta \leq 0 \\
K \delta^{3 / 2} & \delta>0
\end{array},\right. \\
& K=\pi k E^{\prime}\left(\frac{R \varepsilon}{4.5 \zeta^{3}}\right)^{1 / 2},
\end{aligned}
$$

where $K$ is the load deformation coefficient and can be calculated as proposed by Harmrock [19].

Because the size of contact ellipse in the $y_{\text {con }}$ direction is generally very small, the change in the sliding velocity along this direction can be ignored, as shown in Figure 2. Then, the region of contact ellipse between the ball and the inner ring can be divided into narrow strips in the $x_{\text {con }}$ direction. The vector from the narrow strips $P$ to the center of the ball in the contact coordinate system is

$$
\begin{aligned}
\mathbf{r}_{\mathrm{pb}}^{\mathrm{con}} & =\left[x, y, \sqrt{{R^{\prime 2}-x^{2}}^{2}}-\sqrt{{R^{\prime 2}-a^{2}}^{2}}+\sqrt{1 / 4 D^{2}-a^{2}}\right], \\
R^{\prime} & =\frac{2 \mathrm{fD}}{2 f+1},
\end{aligned}
$$

where a is the semimajor of the contact ellipse. The vector from the narrow strips $P$ to the center of the inner ring in the inertial coordinate system is

$$
\mathbf{r}_{\mathrm{pr}}^{i}=\mathbf{A}_{\mathrm{ri}} \mathbf{A}_{\mathrm{ar}} \mathbf{A}_{\mathrm{cona}} \mathbf{r}_{\mathrm{pb}}^{\mathrm{con}}+\mathbf{r}_{\mathrm{br}}^{i}
$$

The sliding velocity vector of the inner race relative to the ball at strips $\mathrm{P} v_{\mathrm{rb}}^{\text {con }}$ can be calculated as follows:

$$
v_{\mathrm{rb}}^{\mathrm{con}}=v_{\mathrm{pr}}^{\mathrm{con}}-v_{\mathrm{pb}}^{\mathrm{con}},
$$

where $v_{\mathrm{pb}}^{\mathrm{con}}=\mathbf{A}_{\mathrm{icon}}\left[\dot{x}_{b}, 0, \dot{r}_{b}\right]^{\mathrm{T}}+\mathbf{A}_{\mathrm{acon}} \omega_{b}^{a} \times \mathbf{r}_{\mathrm{pb}}^{\mathrm{con}}$

$$
\begin{aligned}
v_{\mathrm{pr}}^{\mathrm{con}} & =\mathbf{A}_{\mathrm{icon}}\left(v_{r}^{i}+\left(\mathbf{A}_{\mathrm{ri}} \omega_{r}^{r}-\left[\dot{\theta}_{b}, 0,0\right]^{\mathrm{T}}\right) \times \mathbf{r}_{\mathrm{pr}}^{i}\right), \\
v_{\mathrm{pb}}^{\mathrm{con}} & \left.=\mathbf{A}_{\mathrm{icon}}\left[\dot{x}_{b}, 0, \dot{r}_{b}\right]^{\mathrm{T}}+\mathbf{A}_{\mathrm{acon}} \omega_{b}^{a} \times \mathbf{r}_{\mathrm{pb}}^{\mathrm{con}}\right), \\
\mathbf{A}_{\mathrm{icon}} & =\mathbf{A}_{\mathrm{acon}} \mathbf{A}_{\mathrm{ra}} \mathbf{A}_{\mathrm{ir}} .
\end{aligned}
$$

The tangential force $T_{P}$ on the strips of $\mathrm{P}$ can be obtained by

$$
\begin{aligned}
& T_{P}=\mu_{P} F_{P}, \\
& F_{P}=\frac{3 F_{n}}{4 a}\left(1-\frac{x_{P}^{2}}{a^{2}}\right) \frac{a}{m},
\end{aligned}
$$

where $x_{\mathrm{p}}$ is the distance between the center of $\mathrm{P}$ and that of the ellipse, $m$ is the number of strips in the semimajor axis, and $\mu_{p}$ is the equivalent friction coefficient obtained by 


$$
\mu_{p}=\mu_{\mathrm{bd}} q_{\mathrm{bd}}+\mu_{\mathrm{hd}}\left(1-q_{\mathrm{bd}}\right) .
$$

In case of a fully flooded EHL, $q_{b d}=0$, and then $\mu_{p}$ can then be written as follows:

$$
\mu_{p}=\mu_{\mathrm{hd}}=\left(A+B\left\|v_{\mathrm{rb}}^{\mathrm{con}}\right\|\right) e^{-C\left\|v_{\mathrm{rb}}^{\mathrm{con}}\right\|}+D,
$$

where $\mathrm{A}, \mathrm{B}, \mathrm{C}$, and $\mathrm{D}$ are the coefficients of a particular lubricant that can be obtained as in Ref. [20]. The components of the tangential force along the semimajor and semiminor axes can be written as follows:

$$
\begin{gathered}
\left\{\begin{array}{c}
T_{\mathrm{Px}}=-T_{P} \sin \theta_{p} \\
T_{\mathrm{Py}}=T_{P} \cos \theta_{p},
\end{array}\right. \\
\theta_{p}=\arcsin \left(\frac{-v_{\mathrm{rb}(1)}^{\mathrm{con}}}{v_{\mathrm{rb}(2)}^{\mathrm{con}}}\right) .
\end{gathered}
$$

The moment vectors of the contact strip acting on the ball and the ring in the contact coordinate system are

$$
\begin{aligned}
& \mathbf{M}_{\mathrm{brp}}^{\mathrm{con}}=\mathbf{r}_{\mathrm{pb}}^{\mathrm{con}} \times\left[T_{\mathrm{px}}, T_{\mathrm{py}}, 0\right]^{\mathrm{T}}, \\
& \mathbf{M}_{\mathrm{rbp}}^{\mathrm{con}}=\left(\mathbf{r}_{\mathrm{pb}}^{\mathrm{con}}+\mathbf{A}_{\mathrm{icon}} \mathbf{r}_{\mathrm{br}}^{i}\right) \times\left[T_{\mathrm{px}}, T_{\mathrm{py}}, 0\right]^{\mathrm{T}} .
\end{aligned}
$$

The total forces and moments on the ball and ring are

$$
\begin{aligned}
& \left\{\begin{array}{l}
\mathbf{F}_{\mathrm{br}}^{a}=\mathbf{A}_{\mathrm{cona}}\left[\sum_{p=1}^{m} T_{\mathrm{px}}, \sum_{p=1}^{m} T_{\mathrm{py}}, F_{n}\right]^{\mathrm{T}}, \\
\mathbf{F}_{\mathrm{rb}}^{i}=-\mathbf{A}_{\mathrm{ai}} \mathbf{F}_{\mathrm{br}}^{a}
\end{array}\right. \\
& \left\{\begin{array}{l}
\mathbf{M}_{\mathrm{br}}^{a}=\mathbf{A}_{\mathrm{cona}} \sum_{p=1}^{m} \mathbf{M}_{\mathrm{brp}}^{\mathrm{con}} \\
\mathbf{M}_{\mathrm{rb}}^{r}=\mathbf{A}_{\mathrm{conr}} \sum_{p=1}^{m} \mathbf{M}_{\mathrm{rbp}}^{\mathrm{con}}
\end{array}\right.
\end{aligned}
$$

2.3. Interactions between Ball and Cage. As shown in Figure 3, $\mathbf{r}_{b}$ and $\mathbf{r}_{c}$ are vectors from the ball and the cage to the center of the inertial coordinate system, respectively, and $\mathbf{r}_{p c}$ is the vector from the center of the cage pocket to that of the cage.

Then, the vector from the center of the ball to that of the cage pocket can be obtained as follows:

$$
\mathbf{r}_{\mathrm{bp}}^{p}=\mathbf{A}_{\mathrm{cp}}\left(\mathbf{A}_{\mathrm{ic}}\left(\mathbf{r}_{b}^{i}-\mathbf{r}_{c}^{i}\right)-\mathbf{r}_{\mathrm{pc}}^{c}\right)
$$

The position of contact between the ball and the pocket can be obtain as follows:

$$
\phi=\arctan \left(\frac{-\mathbf{r}_{\mathrm{bp}(1)}^{p}}{\mathbf{r}_{\mathrm{bp}(2)}^{p}}\right) .
$$

The clearance between the ball and the pocket is

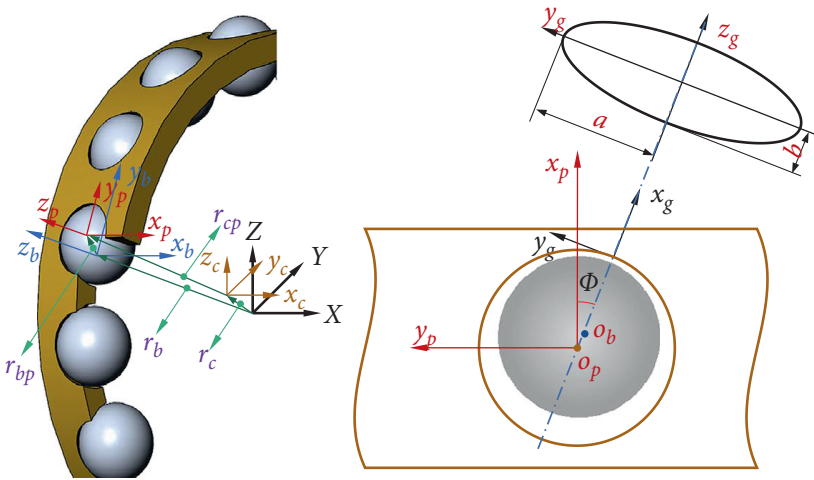

Figure 3: Positional relationships of the ball and the cage.

$$
\begin{aligned}
h_{0} & =\Delta_{\mathrm{bp}}-\sqrt{\mathbf{r}_{\mathrm{bp}(1)}^{p 2}+\mathbf{r}_{\mathrm{bp}(2)}^{p 2}}, \\
\Delta_{\mathrm{bp}} & =\frac{d_{p}-D}{2},
\end{aligned}
$$

where $d_{p}$ is the diameter of the pocket. The critical thickness of the film of oil in the contact state transition $\Delta_{\mathrm{r}}$ is known; if $h_{0}>\Delta_{\mathrm{r}}$, there is no contact between the ball and pocket; if $h_{0} \leq \Delta_{\mathrm{r}}$, there is a contact, and its force and moment can be calculated as described in Section 2.2.

$$
\begin{aligned}
& \left\{\begin{array}{l}
\mathbf{F}_{\mathrm{bc}}^{a}=\mathbf{A}_{\mathrm{ga}} \mathbf{F}_{\mathrm{bc}}^{g} \\
\mathbf{F}_{\mathrm{cb}}^{i}=\mathbf{A}_{\mathrm{gi}}\left(-\mathbf{F}_{\mathrm{bc}}^{g}\right)
\end{array}\right. \\
& \left\{\begin{array}{l}
\mathbf{M}_{\mathrm{bc}}^{a}=\mathbf{A}_{\mathrm{ga}}\left(\mathbf{r}_{\mathrm{gb}}^{g} \times \mathbf{F}_{\mathrm{bc}}^{g}\right) \\
\mathbf{M}_{\mathrm{cb}}^{c}=\left(\mathbf{A}_{\mathrm{gc}} \mathbf{r}_{\mathrm{gp}}^{g}+\mathbf{r}_{\mathrm{pc}}^{c}\right) \times\left(\mathbf{A}_{\mathrm{gc}}\left(-\mathbf{F}_{\mathrm{bc}}^{g}\right)\right)
\end{array}\right.
\end{aligned}
$$

2.4. Interactions between Cage and Ring. As shown in Figure $4, \mathbf{r}_{j c}$ is the vector from the contact point $j$ to the center of the cage and can be written as

$$
\mathbf{r}_{\mathrm{jc}}^{c}=\left[-\frac{L_{c}}{2}, R_{\mathrm{cg}} \sin \phi, R_{\mathrm{cg}} \cos \phi\right]^{\mathrm{T}},
$$

where $L_{c}$ is the width of the cage, $R_{c g}$ is its guide surface, and $\phi$ is the angle between $\mathbf{r}_{j c}$ and the $z_{c}$-axis. The vector from the contact point $j$ to the center of the ring can be written as

$$
\mathbf{r}_{\mathrm{jr}}^{r}=\mathbf{r}_{\mathrm{cr}}^{r}+\mathbf{A}_{\mathrm{cr}} \mathbf{r}_{\mathrm{jc}}^{c} \text {. }
$$

where $R_{r g}$ is the radius of the lip of the raceway.

$$
h_{0}=R_{\mathrm{rg}}-\sqrt{\mathbf{r}_{\mathrm{jr}(2)}^{r}+\mathbf{r}_{\mathrm{jr}(3)}^{r}},
$$

If $h_{0}>\Delta_{\mathrm{r}}$, the force vector on the cage can be calculated by 


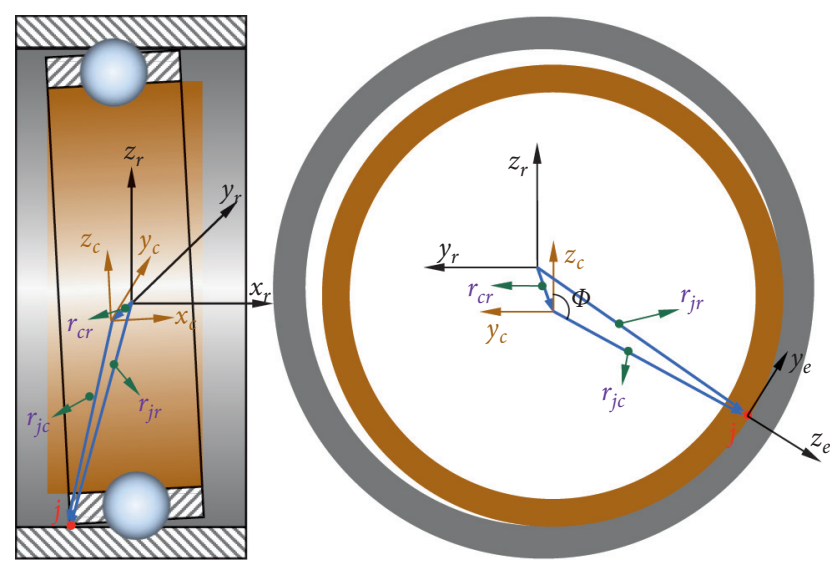

Figure 4: Positional relationships of the cage and the ring. The minimum clearance between the cage and the ring is

$$
\left\{\begin{array}{l}
\mathbf{F}_{\mathrm{cr}(x)}^{e}=\frac{2 \pi \eta_{0} v_{\mathrm{cr}(1)}^{e} R_{\mathrm{cg}}^{2} L_{c}}{\left|R_{\mathrm{cg}}-R_{\mathrm{rg}}\right|} \\
\mathbf{F}_{\mathrm{cr}(y)}^{e}=-\frac{\pi \eta_{0} u_{\mathrm{cr}} \varepsilon^{2} L_{c}^{3}}{4\left|R_{\mathrm{cg}}-R_{\mathrm{rg}}\right|^{2}\left(1-\varepsilon^{2}\right)^{3 / 2}}, \\
\mathbf{F}_{\mathrm{cr}(z)}^{e}=-\frac{\eta_{0} u_{\mathrm{cr}} \varepsilon^{2} L_{c}^{3}}{\left|R_{\mathrm{cg}}-R_{\mathrm{rg}}\right|^{2}\left(1-\varepsilon^{2}\right)^{2}} \\
v_{\mathrm{cr}}^{e}=v_{c}^{e}-v_{r}^{e}, \\
v_{c}^{e}=\mathbf{A}_{\mathrm{ie}} v_{c}^{i}+\mathbf{A}_{\mathrm{ce}} \omega_{c}^{c} R_{\mathrm{cg}}, \\
v_{r}^{e}=\mathbf{A}_{\mathrm{ie}} v_{r}^{i}+\mathbf{A}_{\mathrm{re}} \omega_{r}^{r} R_{\mathrm{rg}},
\end{array}\right.
$$

where $u_{c r}$ is

$$
u_{\mathrm{cr}}=R_{\mathrm{cg}} \omega_{c(1)}^{c}+R_{\mathrm{rg}} \omega_{r(1)}^{r} .
$$

If $h_{0} \leq \Delta_{\mathrm{r}}$, the force vector on the cage can be calculated by Hertz contact as described in Section 2.2.

The force and moment on the cage can be calculated as follows:

$$
\left\{\begin{array}{l}
\mathbf{F}_{\mathrm{cr}}^{i}=\mathbf{A}_{\mathrm{ei}} \mathbf{F}_{\mathrm{cr}}^{e} \\
\mathbf{M}_{\mathrm{cr}}^{c}=\mathbf{r}_{\mathrm{gc}}^{c} \times \mathbf{A}_{\mathrm{ec}} \mathbf{F}_{\mathrm{cr}}^{e}
\end{array}\right.
$$

2.5. Dynamic Equations and Solutions. To study the law of fault vibration response, two translational degrees of freedom were added to the outer ring of the bearing to simulate the measurement of the acceleration sensor in an empirical test, as shown in Figure 5. The differential equation of motion of the outer ring can be written as follows:

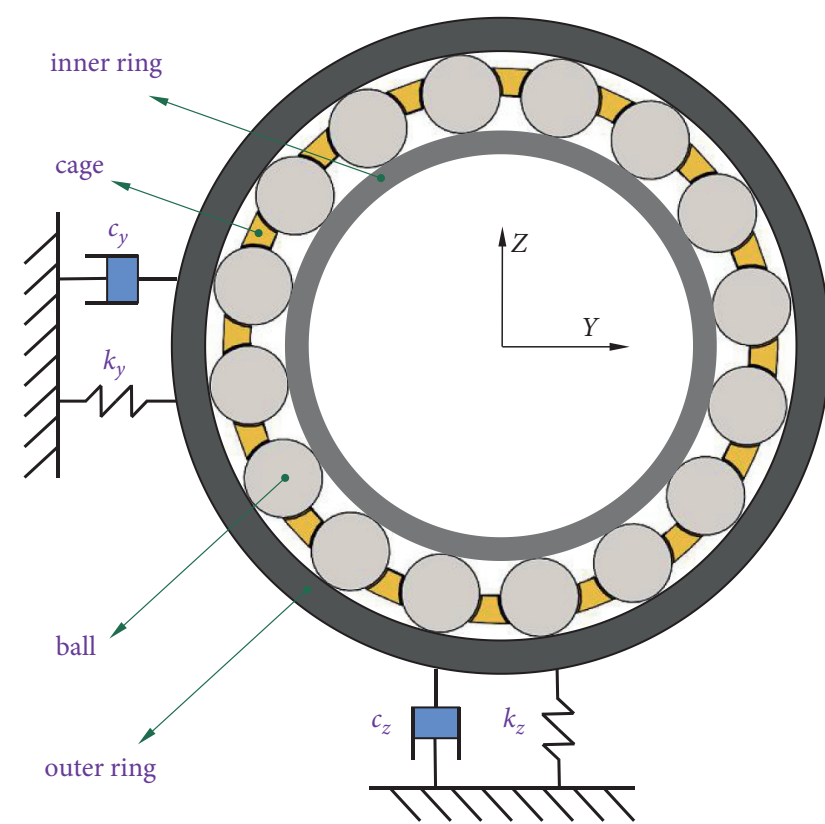

FIgURE 5: Model of the outer ring.

$$
\left\{\begin{array}{l}
m_{o} \ddot{z}_{o}+c_{z} \dot{z}_{o}+k_{z} z_{o}=F_{\mathrm{oz}}, \\
m_{o} \ddot{z}_{o}+c_{y} \dot{y}_{o}+k_{y} y_{o}=F_{\mathrm{oy}}
\end{array}\right.
$$

where $F_{o y}$ and $F_{o z}$ are the loads of the outer ring in the Y and the $Z$ directions, respectively, $m_{o}$ is the mass of the outer ring, $y_{o}$ and $z_{o}$ are the displacements of the outer ring in the $\mathrm{Y}$ and the $Z$ directions, respectively, $c_{y}$ and $c_{z}$ are the respective damping coefficients in the $\mathrm{Y}$ and the $Z$ directions, $k_{y}$ and $k_{z}$ are the respective stiffness coefficients in the $\mathrm{Y}$ and the $Z$ directions, and the coefficients of stiffness and damping were obtained by the modal test of bearing the pedestal of the test rig for bearing.

After all the forces and moments acting on each element of the ball bearing have been calculated, the dynamic equations of each element can be established in different coordinate systems.

Newton's law is used to express the translational motion of any element in the bearing, and the differential equation of motion of the ball can be written as follows:

$$
\left\{\begin{array}{l}
\ddot{x}=\frac{\mathbf{F}_{\mathrm{bro}(1)}^{a}+\mathbf{F}_{\mathrm{bri}(1)}^{a}+\mathbf{F}_{\mathrm{bc}(1)}^{a}}{m_{b}}, \\
\ddot{r}_{b}=\frac{\mathbf{F}_{\mathrm{bro}(3)}^{a}+\mathbf{F}_{\mathrm{bri}(3)}^{a}+\mathbf{F}_{\mathrm{bc}(3)}^{a}+m r_{b} \dot{\theta}_{b}}{m_{b}}, \\
\ddot{\theta}_{b}=\frac{-\mathbf{F}_{\mathrm{bro}(2)}^{a}-\mathbf{F}_{\mathrm{bri}(2)}^{a}+\mathbf{F}_{\mathrm{bc}(2)}^{a}-2 m \dot{r}_{b} \dot{\theta}_{b}}{\mathrm{mr}_{b}} .
\end{array}\right.
$$

The differential equation of motion of the cage can be written as follows: 


$$
\left\{\begin{array}{l}
\ddot{x}_{\mathrm{c}}=\frac{\mathbf{F}_{\mathrm{cr}(1)}^{i}+\sum_{k=1}^{n} \mathbf{F}_{\mathrm{cb}(1) k}^{i}}{m_{c}}, \\
\ddot{y}_{b}=\frac{\mathbf{F}_{\mathrm{cr}(2)}^{i}+\sum_{k=1}^{n} \mathbf{F}_{\mathrm{cb}(2) k}^{i}}{m_{c}}, \\
\ddot{z}_{b}=\frac{\mathbf{F}_{\mathrm{cr}(3)}^{i}+\sum_{k=1}^{n} \mathbf{F}_{\mathrm{cb}(3) k}^{i}}{m_{c}} .
\end{array}\right.
$$

Moreover, the equation of the rotational motion is given by Euler's kinetic equations. Therefore, the equation of rotational motion for each element of the bearing can be written as follows:

$$
\left\{\begin{array}{l}
I_{x} \dot{\omega}_{x}-\left(I_{y}-I_{z}\right) \omega_{y} \omega_{z}=\sum M_{x} \\
I_{y} \dot{\omega}_{y}-\left(I_{z}-I_{x}\right) \omega_{x} \omega_{z}=\sum M_{y} \\
I_{z} \dot{\omega}_{z}-\left(I_{x}-I_{y}\right) \omega_{x} \omega_{y}=\sum M_{z}
\end{array}\right.
$$

The dynamic equations of the ball bearing system can be numerically solved using the step-changing fourth-order Runge-Kutta method. A flowchart of the dynamic simulation program is shown in Figure 6.

2.6. Dynamic Modeling of Compound Faults on Inner and Outer Rings. As shown in Figure 7, the width of the damaged area, and the depths of the inner and outer rings are $w_{\mathrm{di}}, w_{\mathrm{do}}$, and $h_{i d}$, respectively, and $h_{o d} . \theta_{i e}$, and $\theta_{o e}$ are half the center angles corresponding to the damaged areas of the inner and outer rings. $\theta_{i d}$ and $\theta_{o d}$ are the angles of rotation of the center of the damaged area of the inner and outer rings, respectively, and $\theta_{i b}$ and $\theta_{i+1 b}$ are the angles of revolution of the $i$ th and $i+1$ th balls, respectively.

To determine whether the ball enters the damaged area, it is necessary to calculate the center angle corresponding to the damage and the center of the ball:

$$
\left\{\begin{array}{l}
\theta_{\text {bdi }}=\bmod \left(\theta_{i+1 b}, 2 \pi\right)-\bmod \left(\theta_{\mathrm{id}}, 2 \pi\right), \\
\theta_{\text {bdo }}=\bmod \left(\theta_{\mathrm{ib}}, 2 \pi\right)-\bmod \left(\theta_{\mathrm{od}}, 2 \pi\right) .
\end{array}\right.
$$

If $\theta_{b d i}<\theta_{i e}$, the ball enters the damaged area of the inner ring and otherwise does not. And if $\theta_{b d o}{ }^{<} \theta_{o e}$, the ball enters the damaged area of the outer ring and otherwise does not.

In case the ball does not enter the damaged area, the contact deformations of the ball and the ring can be calculated according to Section 2.2. If it does enter the damaged area, the contact deformations need to be calculated by considering the additional deformation caused by the damage. The total deformations are calculated as

$$
\begin{aligned}
& \delta_{\mathrm{di}}= \begin{cases}\delta_{i}-h_{\mathrm{id}}, & \left|\theta_{\mathrm{bdi}}\right|<\theta_{\mathrm{ie}}, \\
\delta_{i}, & \text { else },\end{cases} \\
& \delta_{\mathrm{do}}= \begin{cases}\delta_{o}-h_{\mathrm{od}}, & \left|\theta_{\mathrm{bdo}}\right|<\theta_{\mathrm{oe}} \\
\delta_{o}, & \text { else },\end{cases}
\end{aligned}
$$

The contact loads are still calculated according to the Hertz contact load formula in Section 2.2.

Moreover, as shown in Figure 8, the direction of the contact load changes when the ball enters the damaged area. The contact points in the inner and outer rings are $G_{i}$ and $G_{o}$, respectively. According to the normal bearing model, the direction of the contact load refers to the center of curvature of the ring and is described in the contact coordinate system. However, once damage has been introduced, the contact load refers to the center of mass of the ball through $G_{i}$ or $G_{o}$.

For the convenience of description, the damage contact coordinate systems of $G_{i}^{-} x_{i d c}-y_{i d c}-z_{i d c}$ and $G_{o}-x_{o d c}-y_{o d c}-z_{o d c}$ are established at contact points $G_{i}$ and $G_{o}$, respectively.

The contact loads can then be obtained as follows:

$$
\begin{aligned}
& F_{i}^{\mathrm{dc}}=K \delta_{\mathrm{di}}, \\
& F_{o}^{\mathrm{dc}}=K \delta_{\mathrm{do}} .
\end{aligned}
$$

To introduce the mathematical expression of damage to the dynamic bearing model, it is necessary to transform the damage contact coordinate system into the normal bearing contact coordinate system. For this, it is necessary to obtain the transformation matrix between the coordinate systems. The radius of the ball and the radius of curvature of the rings are known. The angle $\Psi_{i(o)}$ between the $z_{i(o) c}$-axis and the $z_{i(o)}$ $d c$-axis can be easily determined according to the geometric relationship. The transformation matrix can be expressed as

$$
\mathbf{A}_{i(o) \mathrm{dcc}}=\mathbf{A}\left(\psi_{i(o)}, 0,0\right) .
$$

The flowchart of the simulation program of the dynamic model of compound faults on the inner and outer rings is shown in Figure 9.

\section{Results and Discussion}

The angular contact ball bearing $\mathrm{H} 7005 \mathrm{C}$ was taken as a research object. H7005 C is often used as the spindle bearing in high-speed machine tools; its limit speed is 33000r/min; the range of speed of the tool spindle is generally within $12000 \mathrm{r} / \mathrm{min}$. The parameters of its geometry and the operating conditions are summarized in Table 1.

Figures 10 and 11 show the vibration signals in case of a single fault in the inner and outer rings in the time domain, and Figure 12 shows the signals in case of a compound fault. The periodicity of the former set of signals was clear.

A comparison shows that the components of noise of vibration signals in case of a compound fault increased and thus did not have significant periodicity.

The theoretical characteristic frequency of single faults in the inner and outer rings can be calculated according to the following formula:

$$
\left\{\begin{array}{l}
f_{0}=\frac{Z}{2} \times \frac{n}{60} \times\left(1-\frac{D_{w}}{d_{m}} \cos \alpha\right), \\
f_{i}=\frac{Z}{2} \times \frac{n}{60} \times\left(1+\frac{D_{w}}{d_{m}} \cos \alpha\right),
\end{array}\right.
$$




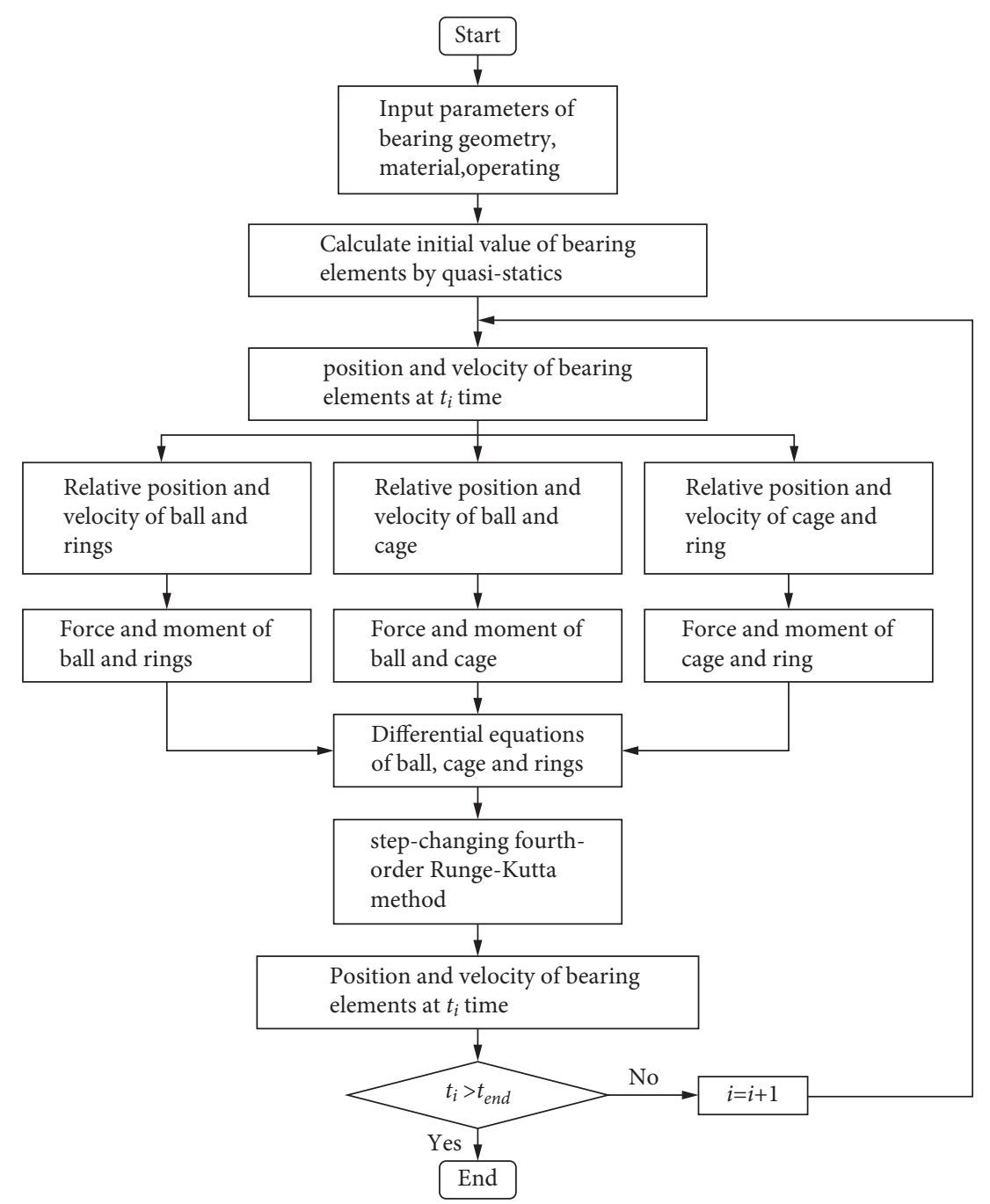

Figure 6: Flowchart of the dynamic simulation.

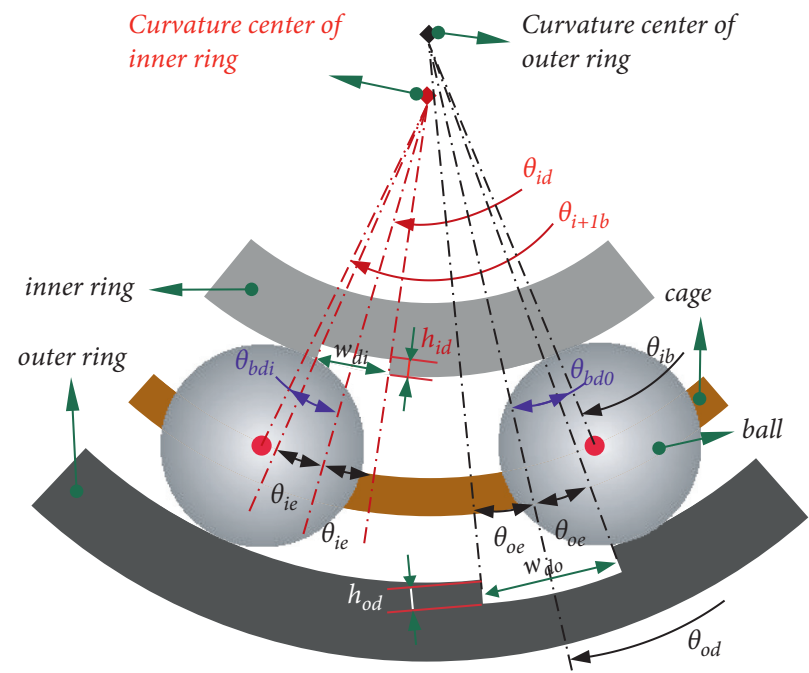

FiguRe 7: Relationship between ball and fault. 


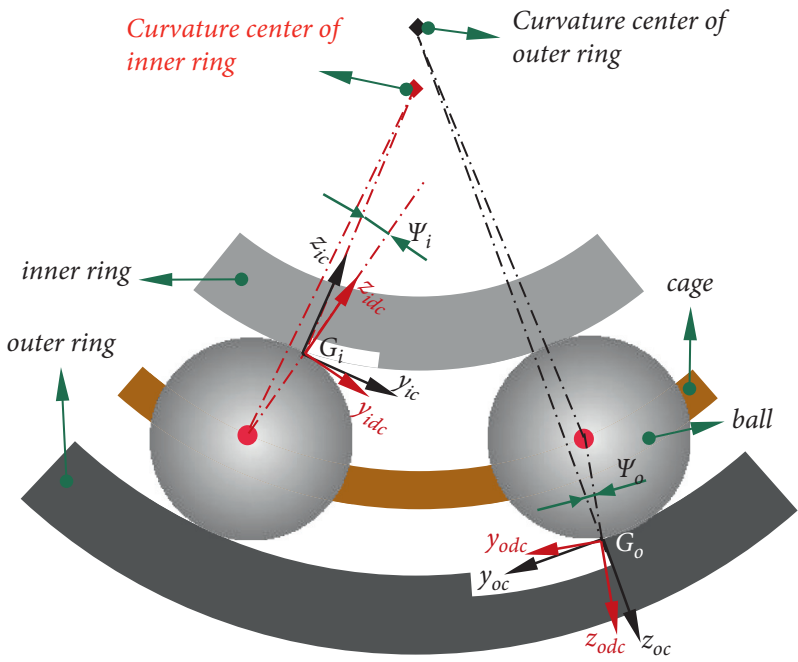

FIgURE 8: Change in the direction of the contact force.

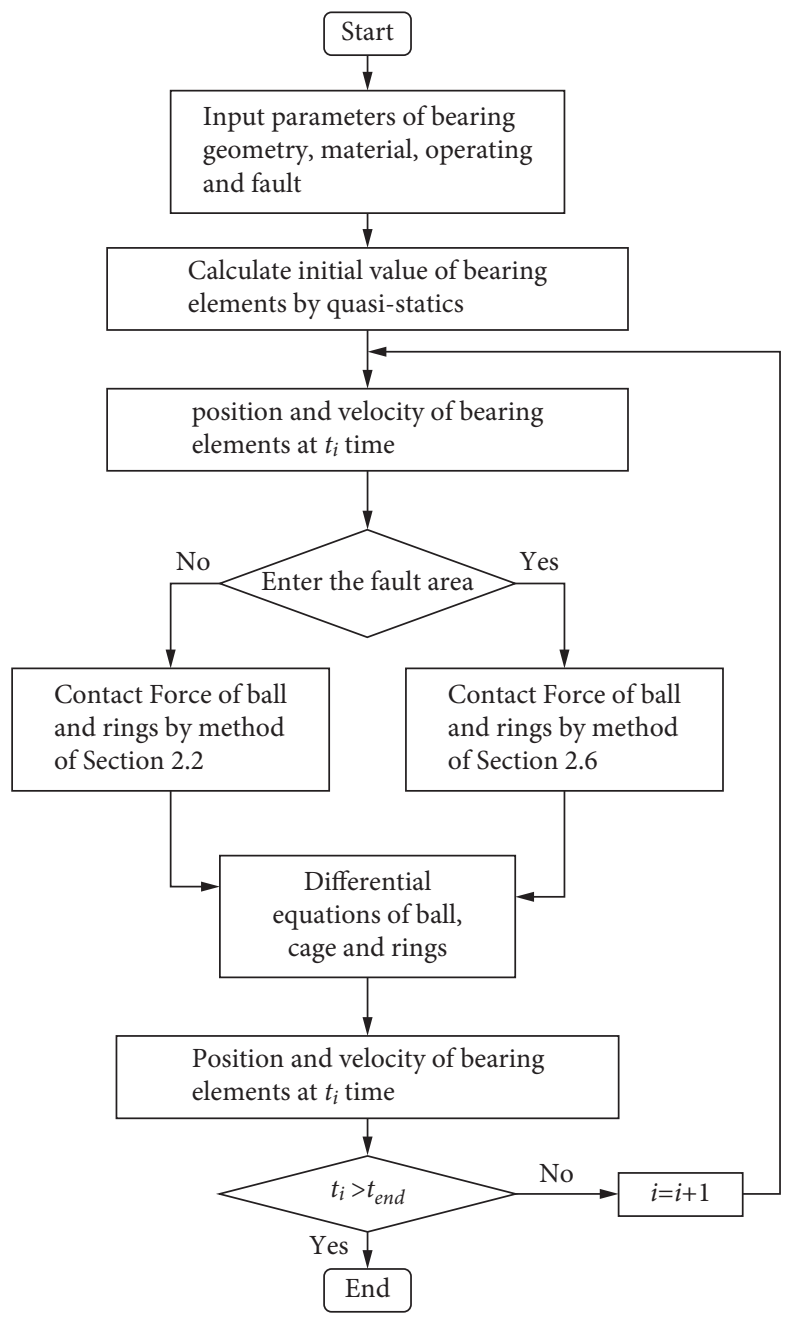

Figure 9: Flowchart of the dynamic fault simulation. 
TABLE 1: Parameters of bearing and operating conditions.

\begin{tabular}{|c|c|}
\hline Parameters & Value \\
\hline Diameter of inner ring/mm & 25 \\
\hline Diameter of bottom of groove of inner ring $/ \mathrm{mm}$ & 30.425 \\
\hline Density of inner ring material $/ \mathrm{g} / \mathrm{cm}^{3}$ & 7.83 \\
\hline Diameter of outer ring $/ \mathrm{mm}$ & 47 \\
\hline Diameter of bottom of groove of outer ring/mm & 41.562 \\
\hline Density of outer ring material $/ \mathrm{g} / \mathrm{cm}^{3}$ & 7.83 \\
\hline Diameter of balls/mm & 5.556 \\
\hline Number of balls & 16 \\
\hline Width of bearing/mm & 12 \\
\hline Contact angle $/^{\circ}$ & 15 \\
\hline Inner diameter of cage $/ \mathrm{mm}$ & 36 \\
\hline Outer diameter of cage $/ \mathrm{mm}$ & 39.27 \\
\hline Diameter of cage pocket/mm & 5.89 \\
\hline Density of cage material $/ \mathrm{g} / \mathrm{cm}^{3}$ & 1.3 \\
\hline Dynamic viscosity of grease $/ \mathrm{mm}^{2} / \mathrm{sec}$ & 5.1 \\
\hline Radial load/N & 300 \\
\hline Axial load/N & 100 \\
\hline Initial rotational speed of inner $\mathrm{ring} / r / \mathrm{min}$ & 1000 \\
\hline Stable rotational speed of inner $\mathrm{ring} / r /$ min (linear increase to stable speed within 0.1 s) & 10000 \\
\hline Initial step size & $0.0001 \mathrm{~s}$ \\
\hline Simulation duration & $0.5 \mathrm{~s}$ \\
\hline Diameter of damaged area in inner ring/mm & 0.2 \\
\hline Depth of damaged area in inner ring/mm & 0.1 \\
\hline Diameter of damaged area in outer ring/mm & 0.2 \\
\hline Depth of damaged area in outer $\mathrm{ring} / \mathrm{mm}$ & 0.1 \\
\hline
\end{tabular}

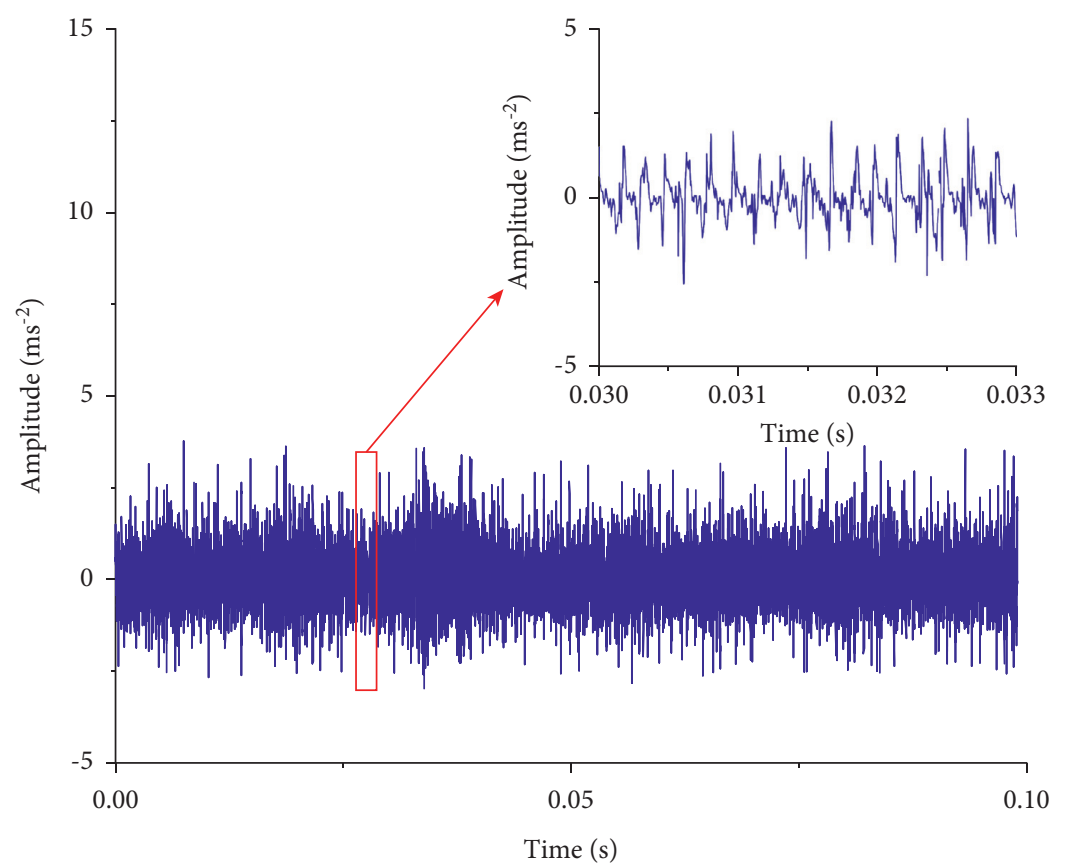

Figure 10: Vibration signals of single inner fault in the time domain.

where $f_{i}=1532.1 \mathrm{~Hz}$ and $f_{o}=1134.6 \mathrm{~Hz}$.

Figures 13 and 14 show the spectral analysis of vibration signals in case of a single fault in the inner and outer rings. The frequency components in the figures are clean, and the characteristic fault frequency is prominent. These results were consistent with the theoretical calculations, verifying the correctness of the model.

To overcome the influence of noise as shown in Figure 12, the compound fault signals were decomposed by dual-tree complex wavelet transform, and a series of 


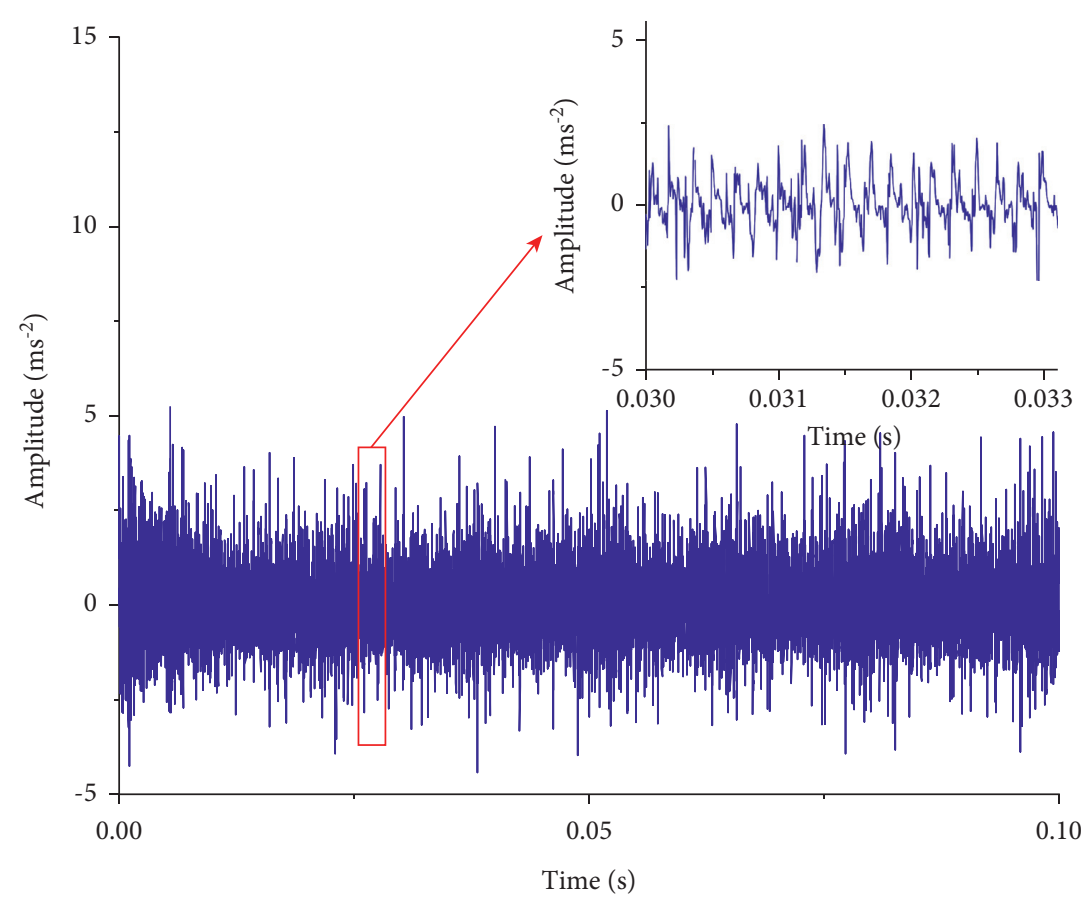

FIGURE 11: Vibration signals of single outer fault in the time domain.

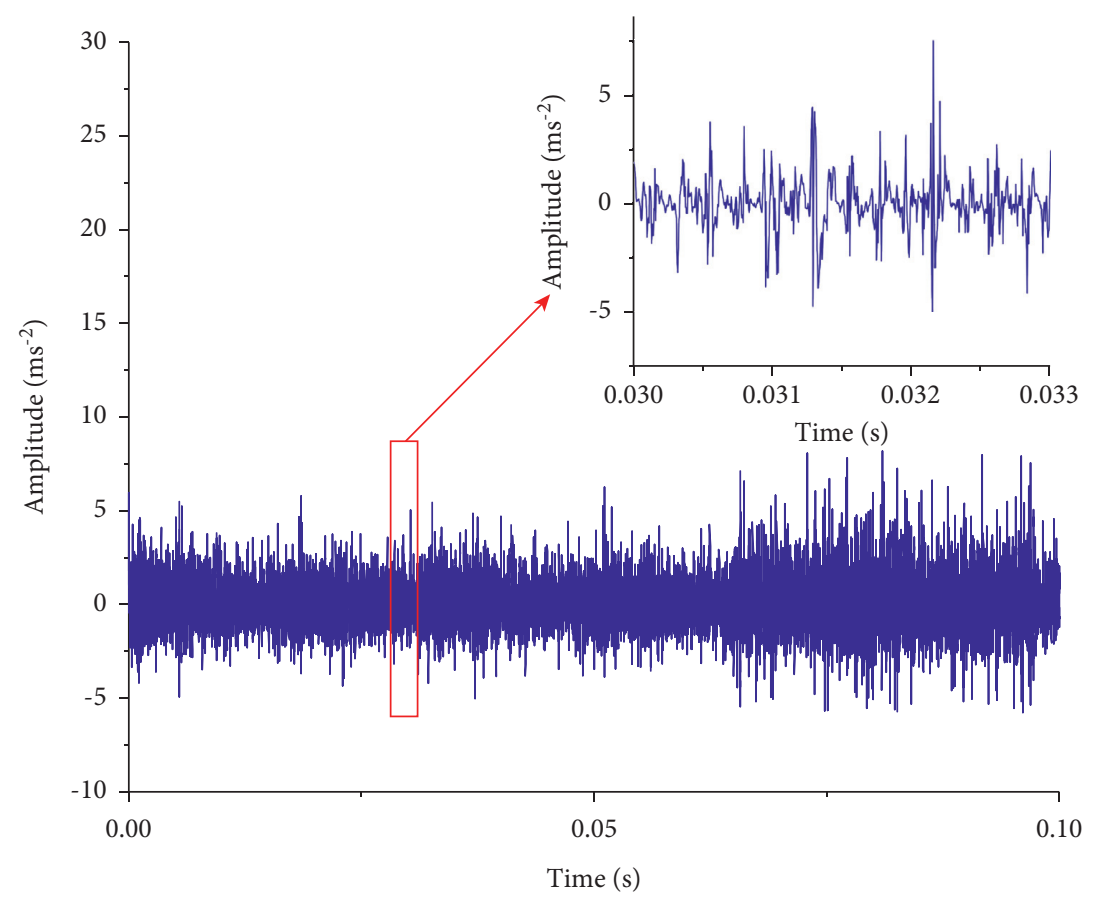

FIGURE 12: Vibration signals of compound fault in the inner and outer rings in the time domain.

decomposed components were obtained, as shown in Figure 15. According to the kurtosis criterion, the maximum component of kurtosis was selected for spectral analysis.

A spectral analysis of the second decomposed component in Figure 15 was then conducted. Figure 16 shows the characteristic frequency of compound faults of the inner and outer rings and the doubling of their frequencies.
Different sizes of damage to the inner and outer rings were considered to verify the accuracy of the proposed method. A three-factor four-level orthogonal experiment was arranged, as shown in Table 2. As shown in Figure 17, the nine groups of simulations obtained a clear characteristic frequency of the compound fault by using the method proposed in this paper. 


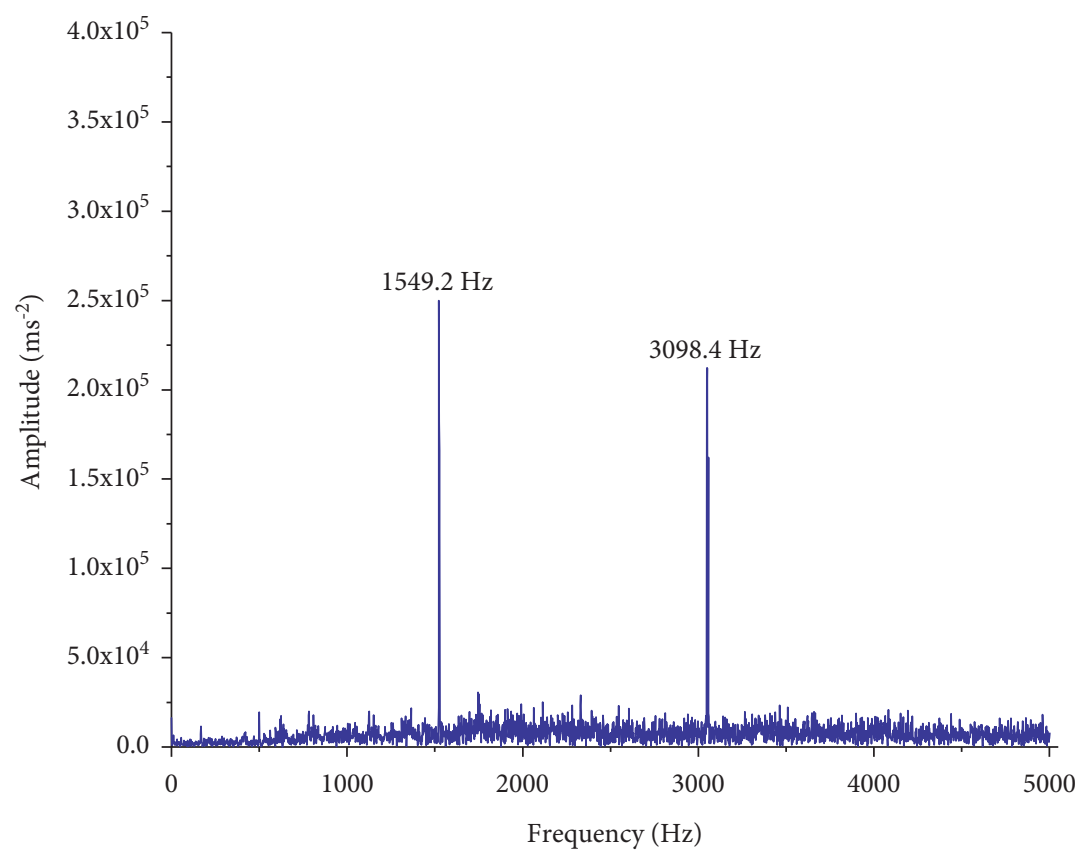

FIGURE 13: Envelope spectra of single fault in the inner ring.

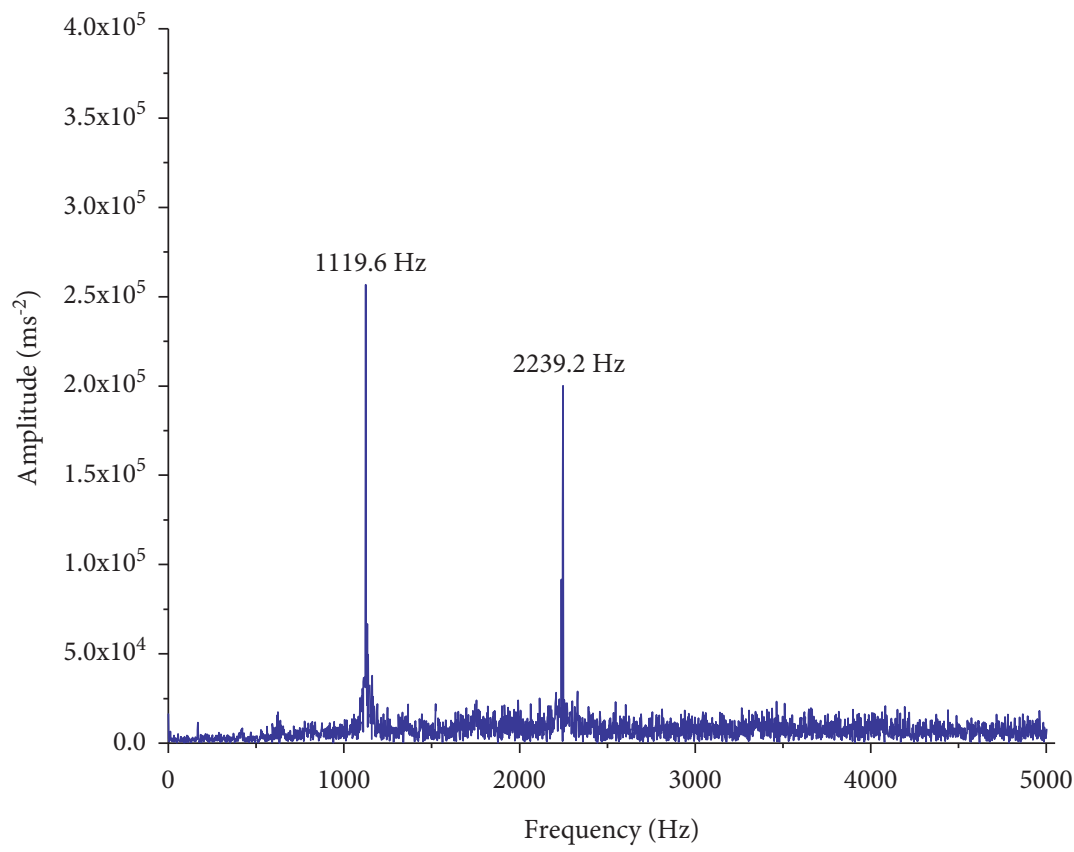

FIGURE 14: Envelope spectra of single fault in the outer ring.

To verify the correctness of the proposed model and the results of analysis, experiments were conducted on a bearing test rig, as shown in Figure 18. The bearing test rig consisted of a mechanical structure, driving system, and loading device. The mechanical structure was a cantilever structure, two sets of bearing were used to support the spindle, and the test bearing was located at one end of it. The drive system used the direct drive of the motor to rotate the spindle. The loading device was loaded by a hydraulic cylinder that could apply axial and radial loads on the bearing. The load was reflected through the pressure of the hydraulic cylinder, as shown in Figure 19.

As shown in Figure 20, the tested bearing was an angular contact ball bearing with a compound faults in the inner and outer rings constructed by using EDM technology. And the parameters of the bearing are listed in Table 1.

During data processing, the dual-tree complex wavelet transform was used to decompose the vibration signals, and spectral analysis was carried out. As shown in Figure 21, in comparison with Figure 16, the frequency component was 

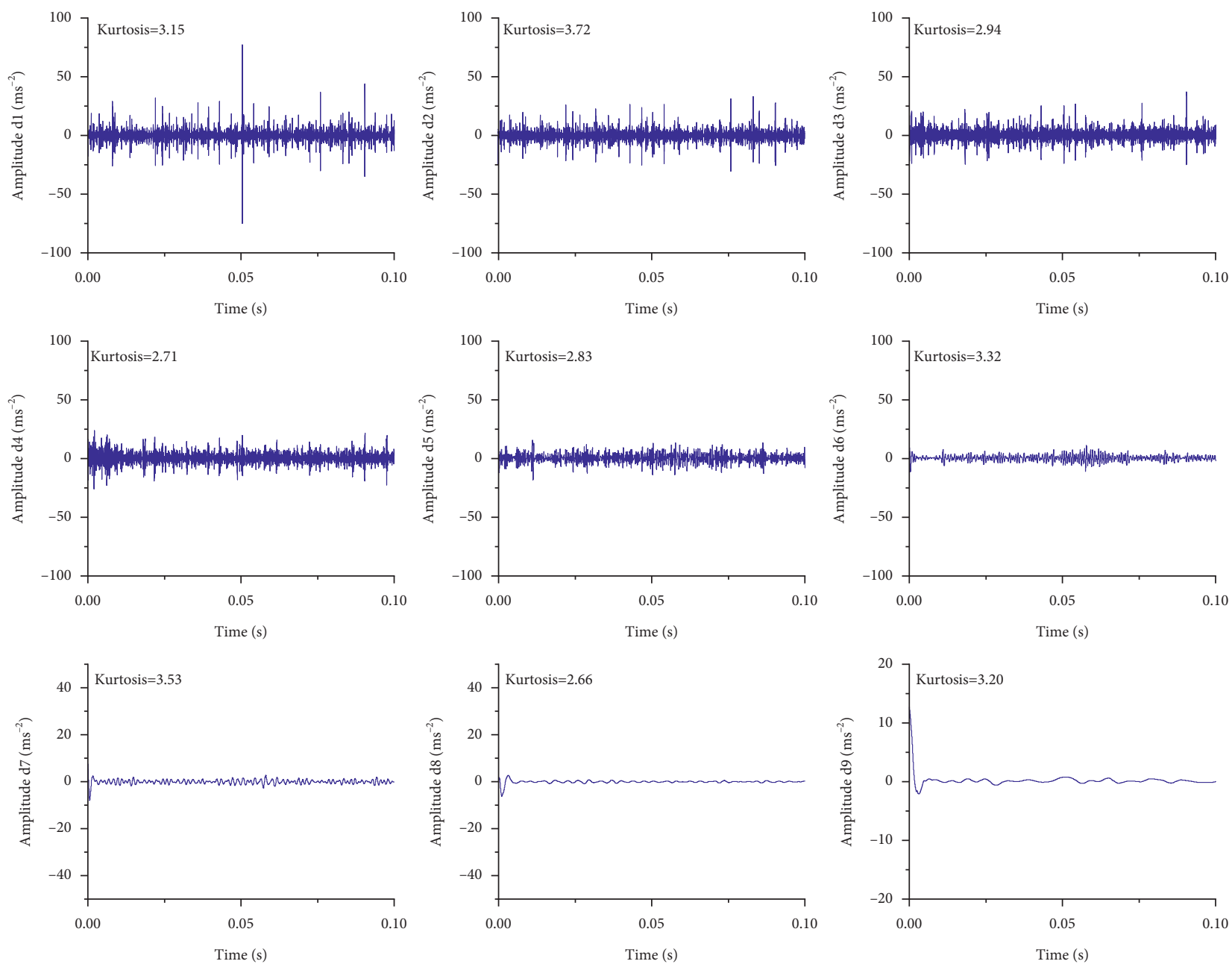

FIGURE 15: Signal decomposition based on dual-tree complex wavelet transform.

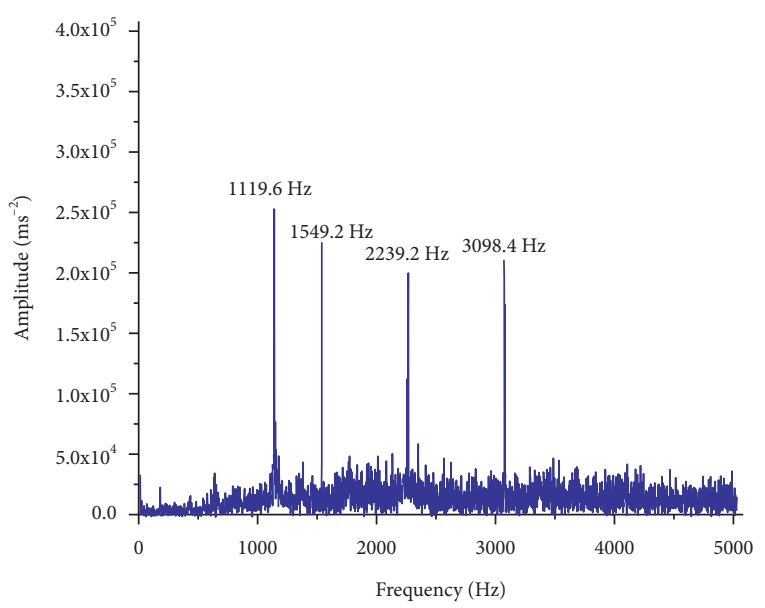

Figure 16: Envelope spectra of compound fault in the inner and outer rings.

more complex, and many unknown frequencies appeared. Although some errors occurred, the characteristic frequency of the test was consistent with the simulation value. The correctness of the proposed was thus verified.
To further verify the accuracy of the proposed method, we first tested the bearing according to the parameters listed in Table 2 and then examined it on the bearing test rig. Finally, as shown in Figure 22, the nine groups of tests 
TABLe 2: Three-factor four-level experimental design.

\begin{tabular}{lcccc}
\hline $\begin{array}{l}\text { Serial } \\
\text { number }\end{array}$ & $\begin{array}{c}\text { Diameter of damaged area in inner ring/ } \\
\text { mm }\end{array}$ & $\begin{array}{c}\text { Depth of damaged area } \\
\text { in inner ring/mm }\end{array}$ & $\begin{array}{c}\text { Diameter of damaged } \\
\text { area } \\
\text { in outer ring/mm }\end{array}$ & $\begin{array}{c}\text { Depth of damaged area in } \\
\text { outer ring/mm }\end{array}$ \\
\hline 1 & 0.1 & 0.05 & 0.1 & 0.05 \\
2 & 0.1 & 0.1 & 0.2 & 0.1 \\
3 & 0.1 & 0.15 & 0.3 & 0.15 \\
4 & 0.2 & 0.05 & 0.1 & 0.1 \\
5 & 0.2 & 0.1 & 0.2 & 0.15 \\
6 & 0.2 & 0.15 & 0.2 & 0.05 \\
7 & 0.3 & 0.05 & 0.3 & 0.15 \\
9 & 0.3 & 0.1 & 0.1 & 0.1 \\
\hline
\end{tabular}
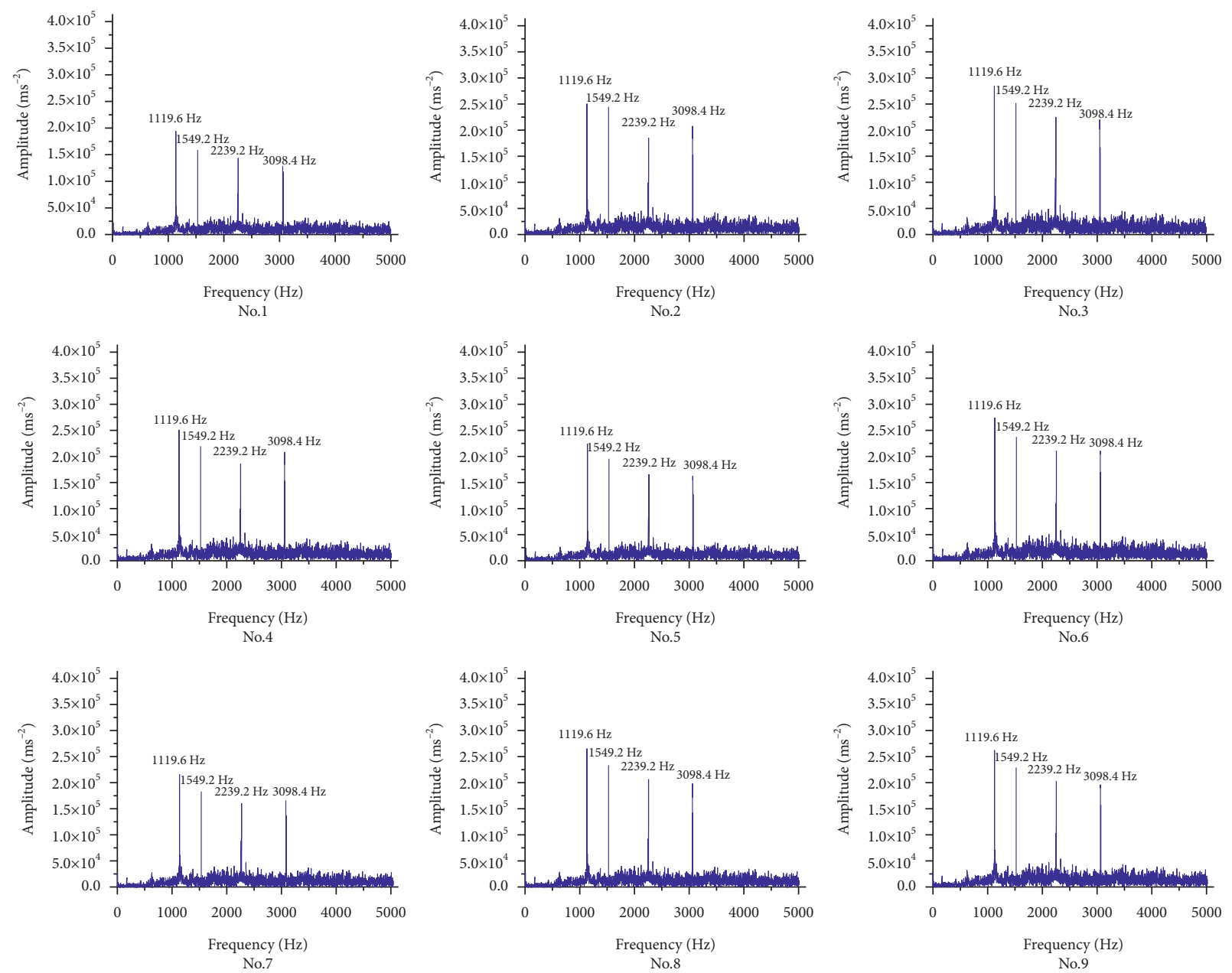

FigURE 17: envelope spectra of compound fault in the inner and outer rings of different sizes of damage obtained in the simulation.

yielded the characteristic frequency of the compound fault by using the proposed method.

Errors occurred between the theoretical and the simulated values. The influence of the operating parameters on the errors was thus examined. As shown in Figure 23, the simulation value was greater than the theoretical value in case of a single fault in the inner ring, and the error increased with the rotating speed. 
Axial loading device Radial loading device Electric Motor

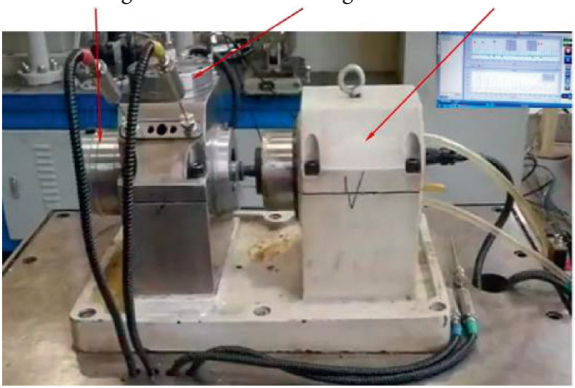

Figure 18: Bearing test rig.

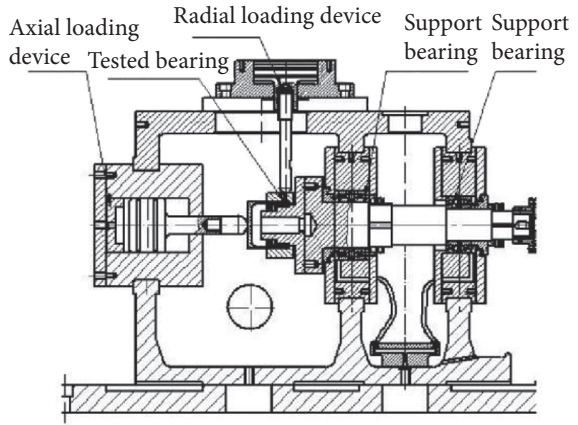

FIgURE 19: Loading diagram of bearing test rig.

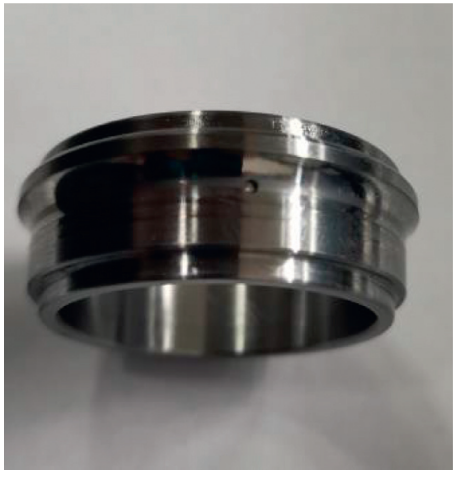

(a)

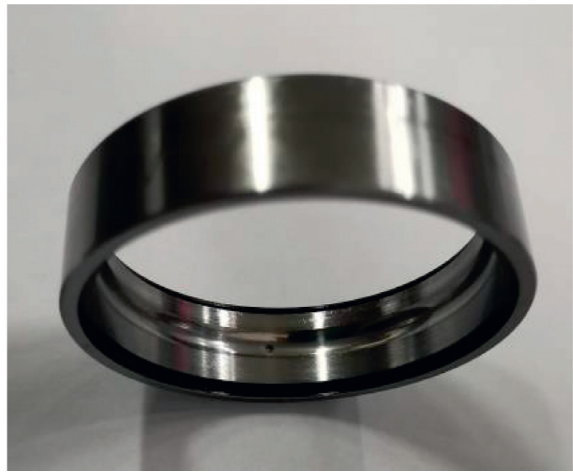

(b)

FIGURE 20: Morphology of compound faults. (a)Inner ring (b)Outer ring.

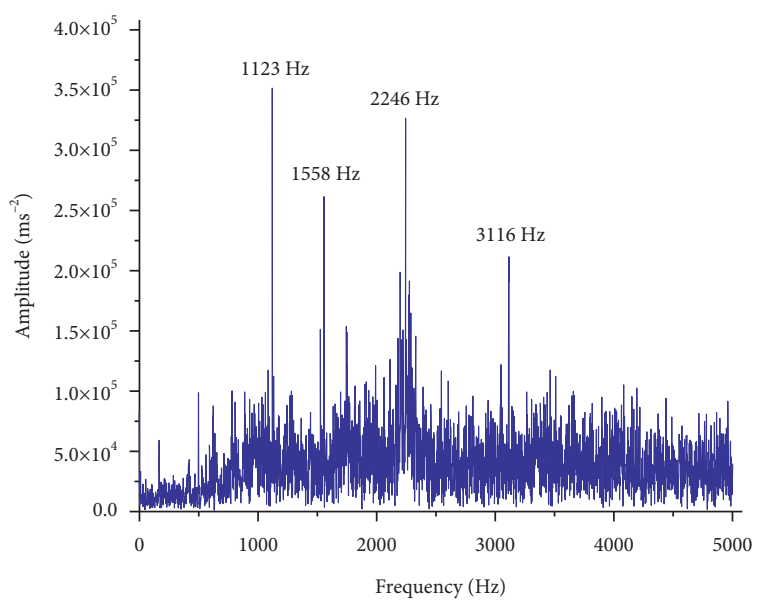

FIGURE 21: Envelope spectra of test acceleration responses of the bearing with a compound fault in the inner and outer raceways. 

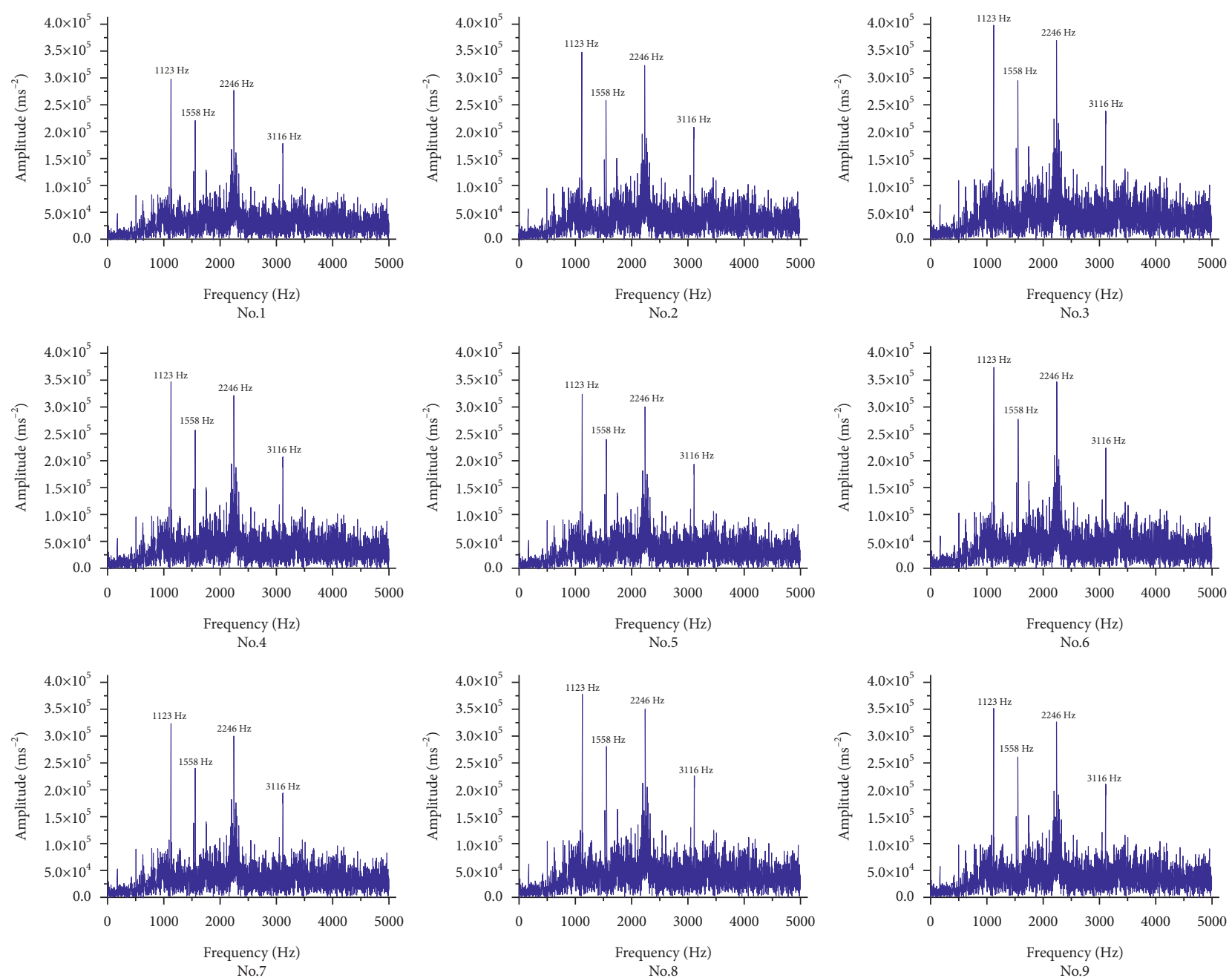

FIGURE 22: Envelope spectra of compound fault in the inner and outer rings of different sizes of damage obtained through experiments.

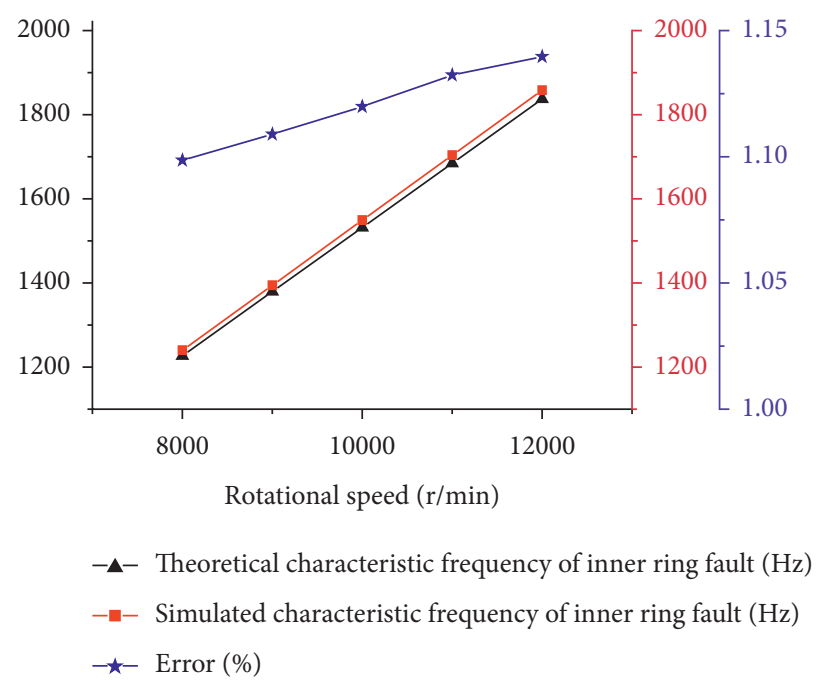

FIGURE 23: Influence of speed of rotation on the characteristic frequency of single fault in the inner ring $\left(F_{\mathrm{r}}=300(\mathrm{~N})\right.$ and $\left.F_{\mathrm{a}}=100 \mathrm{~N}\right)$. 


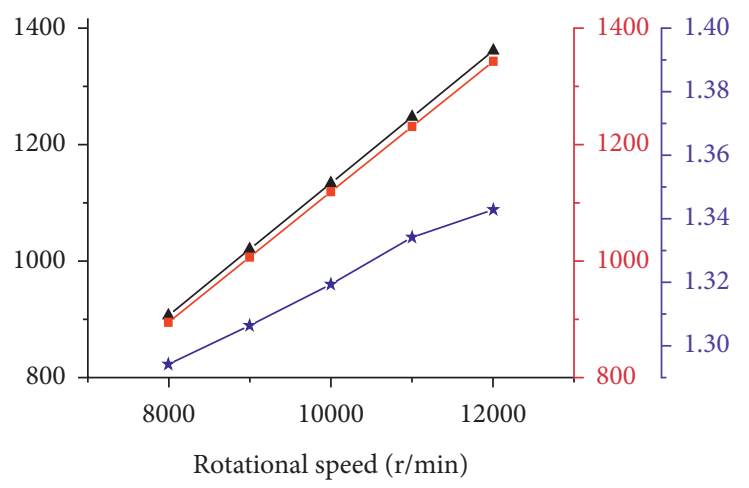

- $\boldsymbol{\Delta}$ - Theoretical characteristic frequency of outer ring fault $(\mathrm{Hz})$

- - Simulated characterisic frequency of outer ring fault $(\mathrm{Hz})$

$-\star-$ Error (\%)

Figure 24: Influence of speed of rotation on the characteristic frequency of single fault in the outer ring $\left(F_{\mathrm{r}}=300(\mathrm{~N}) F_{\mathrm{a}}=100 \mathrm{~N}\right)$.

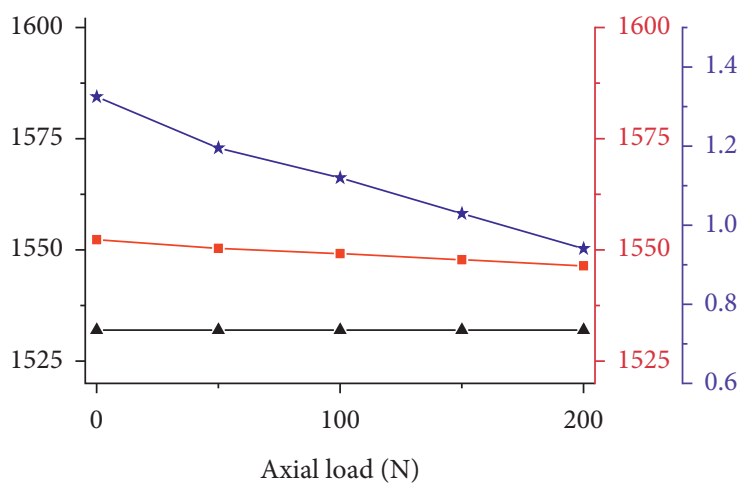

- $\mathbf{\Delta}$ - Theoretical characteristic frequency of inner ring fault $(\mathrm{Hz})$

- - Simulated characteristic frequency of inner ring fault $(\mathrm{Hz})$

- - Error (\%)

FIGURE 25: Influence of axial load on the characteristic frequency of single fault in the inner $\operatorname{ring}\left(F_{\mathrm{r}}=300(\mathrm{~N})\right.$ and $\left.(\mathrm{n})=10000 \mathrm{r} / \mathrm{min}\right)$.

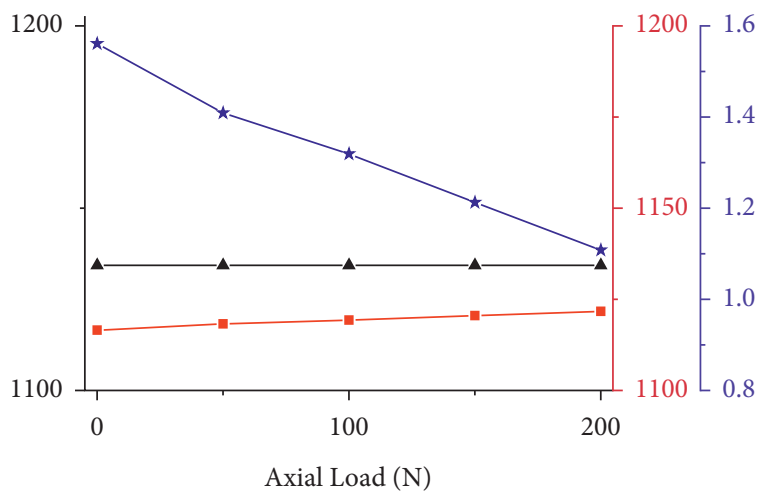

- $\mathbf{\Delta}$ - Theoretical characteristic frequency of outer ring fault $(\mathrm{Hz})$

$-\square-$ Simulated characteristic frequency of outer ring fault $(\mathrm{Hz})$

$-\star-$ Error $(\%)$

FiguRE 26: Influence of axial load on the characteristic frequency of single fault in the outer ring $\left(F_{\mathrm{r}}=300(\mathrm{~N})\right.$ and $\left.(\mathrm{n})=10000 \mathrm{r} / \mathrm{min}\right)$.

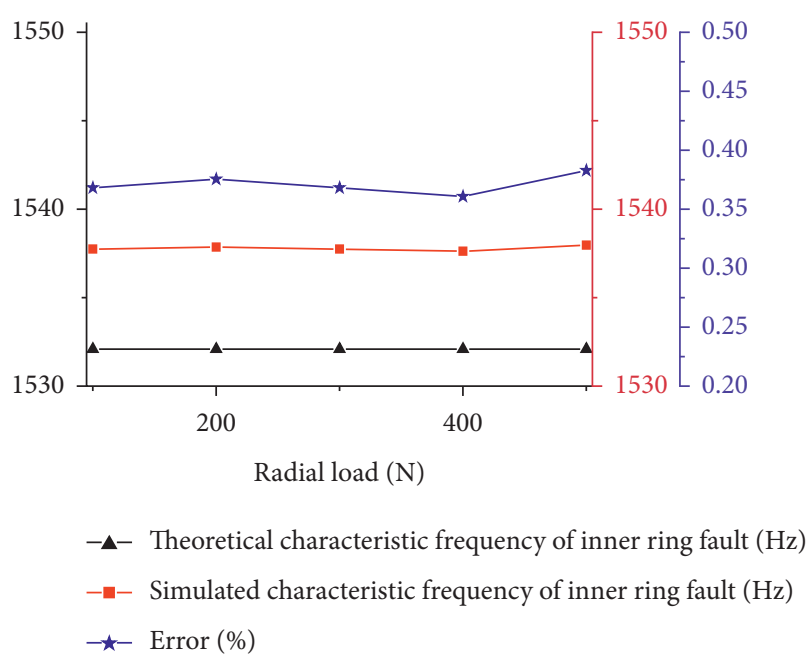

FIGURE 27: Influence of radial load on the characteristic frequency of single fault in the inner ring $\left(F_{\mathrm{a}}=100(\mathrm{~N})\right.$ and $(\mathrm{n})=10000 \mathrm{r} /$ $\min )$.

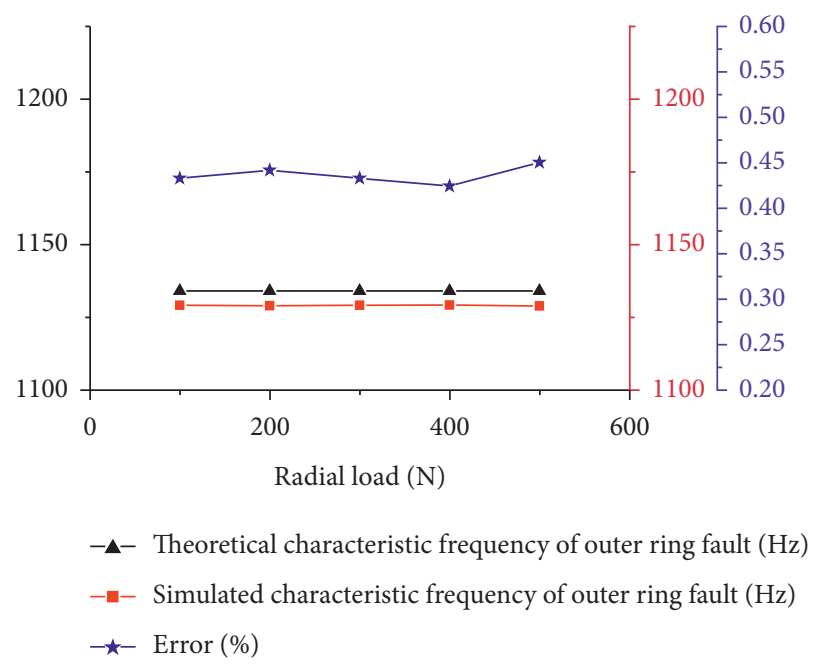

FIGURE 28: Influence of radial load on the characteristic frequency of single fault in the outer ring $\left(F_{\mathrm{a}}=100(\mathrm{~N})\right.$ and $(\mathrm{n})=10000 \mathrm{r} /$ $\min )$.

Similarly, as shown in Figure 24, the error increased with rotating speed in case of a single fault in the outer ring but the simulation value was less than the theoretical value.

As shown in Figures 25 and 26, regardless of whether the inner or outer ring was involved, the error decreased with an increase in the axial load. In case of a fault in the inner ring, the simulation value was greater than the theoretical value, while for a fault in the outer ring, the simulation value was less than the theoretical value.

From Figures 27 and 28, it is clear that the radial load had little effect on the error.

As for the theoretical value and simulation value of characteristic frequency, the law is consistent with the previous conclusion. 


\section{Conclusions}

This paper proposed and verified a dynamic model of an angular contact ball bearing, based on Gupta's dynamic modeling method, by considering changes in the deformation and the direction of contact load when the ball passed through a damaged area. The vibration response signals in case of single and compound faults in the inner and outer rings were studied by using this model.

(1) For a single fault in the inner and outer rings, the signal of the vibration response of the bearing in the time domain exhibited a certain periodicity, and the frequency of fault in the envelope spectrum was clear.

(2) For compound faults in the inner and outer rings, the noise component of the signal increased in the time domain, and a period was not prominent. Once the vibration signal had been processed by the dual-tree complex wavelet method, the characteristic frequency of the complex fault was identified.

(3) Errors occurred between the theoretical and the simulated values and increased with an increase in the rotational speed and decreased with an increase in the axial load. The influence of radial load was minor, however. In case of a fault in the inner ring, the simulation value was greater than the theoretical value, whereas it was smaller than the theoretical value in case of a fault in the outer ring.

\section{Data Availability}

The data used to support the findings of this study are available from the corresponding author upon request.

\section{Conflicts of Interest}

The authors declare that they have no conflicts of interest.

\section{Acknowledgments}

This work was supported by the National Science Funds of China (No. 51805151), and the Key Scientific Research Projects of Colleges and Universities in Henan Province (No: 19A460019).

\section{References}

[1] J. Liu and Y. Shao, "Overview of dynamic modelling and analysis of rolling element bearings with localized and distributed faults," Nonlinear Dynamics, vol. 93, 2018.

[2] S. Wang, W. Huang, and Z. K. Zhu, "Transient modeling and parameter identification based on wavelet and correlation filtering for rotating machine fault diagnosis," Mechanical Systems and Signal Processing, vol. 25, no. 4, pp. 1299-1320, 2011.

[3] J. Chen, Z. Li, J. Pan et al., "Wavelet transform based on inner product in fault diagnosis of rotating machinery: a review,"
Mechanical Systems and Signal Processing, vol. 70-71, no. MAR., pp. 1-35, 2016.

[4] C. Li, V. Sanchez, G. Zurita, M. C. Lozada, and D. Cabrera, "Rolling element bearing defect detection using the generalized synchrosqueezing transform guided by time-frequency ridge enhancement," ISA Transactions, vol. 60, pp. 274-284, 2015.

[5] J. Ma, L. Zhan, C. Li, and Z. Li, "An improved intrinsic timescale decomposition method based on adaptive noise and its application in bearing fault feature extraction," Measurement Science and Technology, vol. 32, no. 2, p. 20, Article ID 025103, 2021.

[6] A. M. R. Mauricio, J. Qi, W. A. Smith, M. Sarrazin, and K. Gryllias, "Bearing diagnostics under strong electromagnetic interference based on integrated spectral coherence," Mechanical Systems and Signal Processing, vol. 140, Article ID 106673, 2020.

[7] Y. Wang, J. Xiang, R. Markert, and M. Liang, "Spectral kurtosis for fault detection, diagnosis and prognostics of rotating machines: a review with applications," Mechanical Systems and Signal Processing, vol. 66-67, no. JAN, pp. 679-698, 2016.

[8] B. Wang and C. Ding, "Hierarchical frequency-domain sparsity-based algorithm for fault feature extraction of rolling bearings," IEEE Transactions on Instrumentation and Measurement, vol. 69 , no. 99, p. 1, 2020.

[9] A. Hu, S. Xu, L. Xiang, and J. Zhang, "Characteristic analysis of multi-point faults on the outer race of rolling element bearing," Journal of Mechanical Engineering, vol. 56, no. 21, pp. 123-133, 2020.

[10] J. Liu, Y. Xu, and G. Pan, "A combined acoustic and dynamic model of a defective ball bearing," Journal of Sound and Vibration, vol. 50, no. 1, Article ID 116029, 2021.

[11] J. Liu, Z. Xu, L. Zhou, W. Yu, and Y. Shao, "A statistical feature investigation of the spalling propagation assessment for a ball bearing," Mechanism and Machine Theory, vol. 131, pp. 336-350, 2019.

[12] J. Liu, Z. Shi, and Y. Shao, "A theoretical study for the influence of the combined defect on radial vibrations of a ball bearing," Industrial Lubrication \& Tribology, vol. 70, no. 2, p. 00, 2018.

[13] P. K. Gupta, Advanced Dynamics of Rolling Elements, Springer-Verlag, New York, NY, 1984.

[14] L. Niu, H. Cao, and X. Xiong, "Dynamic modeling and vibration response simulations of angular contact ball bearings with ball defects considering the three-dimensional motion of balls," Tribology International, vol. 109, pp. 26-39, 2017.

[15] J. Liu, R. K. Pang, Y. J. Xu, S. Z. Ding, and Q. B. He, "Vibration analysis of a single row angular contact ball bearing with the coupling errors including the surface roundness and waviness," Science China Technological Sciences, vol. 63, no. 6, p. 94, 2020.

[16] Y. Qin, C. Li, F. Cao, and H. Chen, "A fault dynamic model of high-speed angular contact ball bearings," Mechanism and Machine Theory, vol. 143, Article ID 103627, 2020.

[17] H. Li, H. Liu, H. Li, S. Qi, Y. Liu, and F. Wang, "Effect of cagepocket wear on the dynamic characteristics of ball bearing," Industrial Lubrication \& Tribology, vol. 72, no. 7, pp. 905-912, 2020.

[18] H. Li, H. Liu, Y. Liu, S. Qi, and F. Wang, "On the dynamic characteristics of ball bearing with cage broken," Industrial Lubrication \& Tribology, vol. 72, no. 7, pp. 881-886, 2020. 
[19] Hamrock and J. Bernard, Fundamentals of Fluid Film Lubrication, McGraw-Hill, New York, NY, 1994.

[20] Y. Wang, S. Deng, B. Yang, and H. Yang, "Investigation on a new five-parameter rheological model of lubricating oil," Tribology, vol. 27, no. 5, pp. 461-466, 2007. 